\title{
The Back Plate Inscription and eclipse scheme of the Antikythera Mechanism revisited
}

\author{
Paul Iversen $^{1} \cdot$ Alexander Jones $^{2}$ (D) \\ Received: 15 May 2019 / Published online: 24 June 2019 \\ (c) The Author(s) 2019
}

\begin{abstract}
This paper presents a new edition of the Back Plate Inscription (BPI) of the Antikythera Mechanism, a series of descriptions of circumstances associated with eclipses indicated cyclically by the inscriptions of the Mechanism's Saros Dial Scale. Our edition features several significant new readings as well as the confirmation of a disputed reading pertaining to one of the index letters by which the BPI's paragraphs are linked to the specific eclipse glyphs of the Saros Dial. On the basis of the new text, we deduce a revision of the established models for determining which lunar months of the Saros cycle had solar and lunar eclipse possibilities (EPs) and for assigning the solar EPs to paragraphs of the BPI. We further confirm that the entire extant part of the BPI comprises consecutive paragraphs concerning the solar EPs, all inscribed along the right side of the Mechanism's Back Plate, and we revisit the questions of what the BPI's predictions mean and how they relate to the model for the solar EPs.
\end{abstract}

\section{Abbreviations}

IG Inscriptiones Graecae

IGUR Inscriptiones Graecae Urbis Romae

PLond Greek Papyri in the British Museum

POxy. astr. Jones 1999

\section{Communicated by Jed Buchwald.}

Iversen is primarily responsible for Sects. 2 and 3, and Jones for Sect. 4, though both authors have made contributions to each other's sections.

Alexander Jones

alexander.jones@nyu.edu

Paul Iversen

paul.iversen@cwru.edu

1 Department of Classics, Case Western Reserve University, Mather House 111, 11201 Euclid Avenue, Cleveland, OH 44106-7111, USA

2 Institute for the Study of the Ancient World, New York University, 15 East 84th Street, New York, NY 10028, USA 
PTebt The Tebtunis Papyri

SEG Supplementum Epigraphicum Graecum

\section{The Mechanism's eclipse function: previous research and open questions}

The Antikythera Mechanism's eclipse prediction function comprised three elements:

- The spiral Saros Dial and its scale, divided into 223 cells representing the 223 lunar months of a repeating Saros cycle. ${ }^{1}$ About a third of the scale is extant (see Fig. 1). Within certain cells were inscribed "glyphs," highly abbreviated inscriptions indicating the possibility of a solar or lunar eclipse, or both, in the relevant month, together with the time of the syzygy expressed as a whole number hour of day or night. Each glyph has an index letter. The index letters can be seen from the preserved glyphs to run through the Greek alphabet in alphabetic order twice, with horizontal strokes above the letters of the second sequence. ${ }^{2}$ Extrapolating to the end of the scale shows that the second sequence was certainly complete and may have been followed by a small number of glyphs indexed by a curtailed third alphabet or additional special symbols.

- The small circular Exeligmos Dial and its scale, divided into three sectors, entirely extant. The sectors give time corrections to be applied to the times of syzygy recorded on the Saros Dial Scale for repetitions of the Saros cycle. ${ }^{3}$

- The Back Plate Inscription (BPI) occupies spaces on the Back Plate outside the Metonic and Saros Dials. There would originally have been six such spaces, one at each corner of the plate and one on each side of the plate's center where the two dials met; the middle right side space and its inscribed text are partially extant, and the lower right corner space and its inscribed text are entirely extant (see Fig. 1). The BPI is divided into paragraphs consisting of statements that describe circumstances associated with eclipses: solar eclipses in the extant paragraphs and lunar eclipses presumably in other lost parts of the BPI. Each paragraph is followed by a row of index letters that associate the paragraph with the pertinent glyphs on the Saros Dial Scale. ${ }^{4}$

Supposing that the Mechanism was set to some chosen date as indicated by the pointers of the calendrical Metonic, Callippic, and Games Dials on the upper half of the Back Plate, the pointer of the Saros Dial might indicate either a vacant cell or one containing a glyph. If the cell was vacant, no eclipse would be predicted as

\footnotetext{
1 The purpose and structure of the Saros Dial were first explained in Freeth et al. (2006).

2 Freeth et al. (2008); for the use of horizontal strokes to distinguish index letters of the second alphabetic sequence, see Steele $(2011,464)$. The sequences are definitely of the standard 24-letter Greek alphabet and not (for example) the augmented alphabet used for Ionian numerals and incorporating the so-called stigma (actually a form of digamma), qoppa, and sampi.

3 Freeth et al. (2008).

4 See Anastasiou et al. (2016, 192-211).
} 


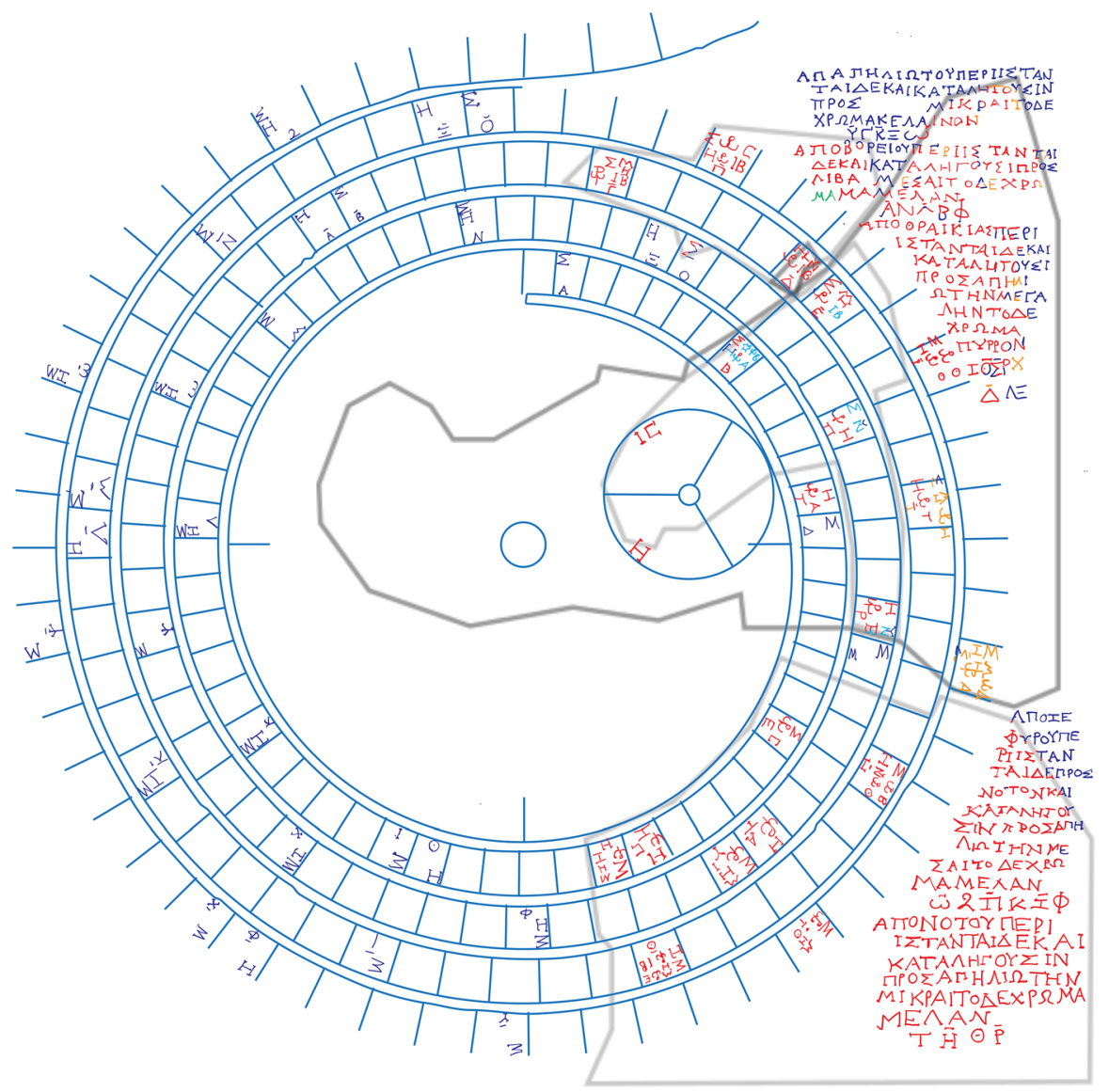

Fig. 1 Composite drawing of the Back Plate Inscription and Saros Dial (Iversen). Colors (digital version only) indicate the sources of the readings. Red indicates text preserved and read on CT, green represents an erasure, orange indicates text read on photographs, purple indicates restored text, blue represents readings that seem to be on the CT, but given the nature of the CT, not certain, and gray lines represent the extant fragments

possible for the month in question. The presence of a lunar glyph would signify that a lunar eclipse was possible at the middle of the month, a solar glyph would signify a possible solar eclipse at the end of the month, and a combined lunar and solar glyph would signify both possibilities. For either type of eclipse, the hour of day or night inscribed in the glyph plus the number of hours (if any) inscribed in whichever sector of the Exeligmos Dial was indicated by its own pointer would be the predicted time of syzygy. The index letter in the glyph would direct the user to the predicted circumstances in the relevant paragraph of the BPI, either in the part devoted to solar eclipses or in the part concerning lunar eclipses according to which kind of eclipse possibility was in consideration. 
Because of the incomplete state of preservation of the Back Plate, we are confronted with two distinct but intertwined questions: To what extent can we reconstruct the missing parts of the Saros Dial inscriptions and BPI? And how much of the theory underlying these inscriptions can we recover? An answer to the second question is not only a prerequisite to answering to the first, but it is also the more interesting one because it informs us not only about the original appearance of an individual, if remarkable, ancient artifact that has come down to us in fragmentary condition, but also about Greek eclipse theory and eclipse prediction in a historical period for which our evidence is extremely scanty.

Initially the evidence that was brought to bear on these questions was limited to the readings of the surviving glyphs. The geometry of the Saros Dial Scale and the pattern of inscribed cells provided the fundamental information, announced in 2006 , that the dial displayed a Saros cycle of eclipse predictions, using the initial letters $\Sigma$ and $\mathrm{H}$ of the Greek words for Moon $\left(\Sigma \varepsilon \lambda \eta^{\prime} v \eta\right)$ and sun $\left({ }^{\circ} \mathrm{H} \lambda{ }_{10 \varsigma}\right)$ to specify the kind of eclipse. ${ }^{5}$ By 2008 , improved readings of the glyphs, closer study of their distribution, and consideration of the index letters as evidence of the numbers of glyphs that were on lost parts of the dial scale resulted in an almost complete reconstruction of the pattern of lunar eclipse possibilities and a partial reconstruction of the solar eclipse pattern, which was shown to have taken some account of the effect of parallax on the incidence of solar eclipses observable in a locality in the northern hemisphere. ${ }^{6}$

Meanwhile, in 2007 Yanis Bitsakis and Emmanuel Georgoudakis had discovered that the BPI, which hitherto lacked either a satisfactory transcription or any convincing interpretation, ${ }^{7}$ comprised descriptions of eclipses, and Alexander Jones thereupon realized that the text was structured as a series of paragraphs linked to groups of the glyphs through their index letters. ${ }^{8}$ By 2012 , it had come to be understood that the assignment of glyphs to groups was partly determined by the Moon's elongation from the nearest node, and Jones had established that the extant paragraphs all pertained to solar eclipses. ${ }^{9}$ A crucial advance was made by Tony Freeth in 2014 , who showed that not only the groups of indexed solar glyphs but also the order of the BPI paragraphs and the order in which the index letters are listed at the end of each paragraph are strictly determined by the Moon's latitude calculated under simplifying conditions. ${ }^{10}$ Among other considerations relating to the restoration of the Mechanism's

\footnotetext{
5 Freeth et al. (2006).

6 Freeth et al. (2008).

7 Price (1974, 50-51) noted the presence of directional references (two out of three, however, being false readings or restorations) but declined to speculate on the inscription's purpose. In Freeth et al. (2006, 588), some connection with eclipses was suggested on the basis of these and two additional spurious readings.

8 Private communications among members of the Antikythera Mechanism Research Project.

9 The dependence on nodal elongation emerged in private communications among Bitsakis, Freeth, Jones, and Steele between 2009 and 2012, and together with the identification of the paragraphs as purely solar was argued in detail in a draft paper (an early version of Anastasiou et al. 2016) written and circulated by Jones in 2012. See also Anastasiou et al. (2016).

10 Freeth $(2014,7-8)$.
} 
Back Plate, Freeth's latitude rule makes it possible to use the attested index letter groups in the BPI to refine the reconstruction of the glyph patterns on the Saros Dial Scale. At a more general level, it helps us to better situate the eclipse theory known to the designers of the Mechanism in relation to Babylonian eclipse theories and to Ptolemy's much more sophisticated modeling of lunar and solar eclipses.

Relying on readings and interpretation of the transcription of the BPI that he offered as the product of a collaboration with Charles Crowther, Freeth additionally argued for a layout of the BPI that was different from the one previously suggested by Jones. Where Jones had hypothesized that all paragraphs relating to solar eclipses occupied the spaces along the right side of the Back Plate while those relating to lunar eclipses were along the left side, Freeth maintained that six solar paragraphs were inscribed in the spaces on both sides of the Saros Dial (two on the left, four on the right) and lunar paragraphs in the spaces on both sides of the Metonic Dial. His reasons were as follows:

1. According to Freeth's model, there ought to be a solar paragraph logically preceding the paragraph comprising BPI lines 6-10 (using the line numbering adopted in the present paper), ${ }^{11}$ but, contrary to the previous Bitsakis-Jones transcription and its restorations, lines $1-5$ could not be that prior paragraph. If it were that paragraph, line 5 would be its row of index letters, ending with omega, but Freeth contends that the single incompletely preserved letter on line 5, which would have been that final index letter, is not omega, but an omicron that cannot be an index letter. He therefore hypothesizes that the missing paragraph was inscribed in the space at the upper left of the Saros Dial.

2. The two paragraphs comprising lines 6-10 and 11-19, which together occupy the space at the upper right of the Saros Dial, are consecutive paragraphs according to the model. The next paragraphs with respect to physical location along the right side of the plate, in the space at the lower right of the dial, are those comprising lines 21-31 and 32-38. These too are consecutive paragraphs according to the model. However, between the last index letter read by Crowther and Freeth in line 19 and the first index letter read in 31 - which is not an ordinary alphabetic letter (with or without a horizontal stroke above) — the model predicts four index letters that therefore must have had their own paragraph logically intervening between 11-19 and 21-31. Freeth therefore hypothesizes that this paragraph was inscribed in the space at the lower left of the dial.

In the 2016 edition and study of the inscriptions of the Mechanism's back dials and plate, Freeth's latitude model for the BPI was embraced as a general principle (with a minor modification to be explained—and repudiated-below). ${ }^{12}$ For

\footnotetext{
11 In the new edition of the BPI presented below, we number the lines starting with the restored line preceding the first preserved line, and a line not previously observed is now included. Hence, our lines 2-19 were numbered $1-18$ in previous editions and discussions, and our lines $21-38$ were previously numbered 19-36.

12 Anastasiou et al. (2016, 197-200).
} 
the layout of the inscription, however, the 2016 study retained the hypothesis that the solar paragraphs all ran down the right side of the Back Plate, though now suggesting that the lunar paragraphs occupied not only the spaces along the left side but also the uppermost space of the right side, to the upper right of the Metonic Dial. With respect to Freeth's arguments for his left-and-right arrangement, the 2016 study asserted the following:

1. The partially preserved letter at the end of the otherwise lost line 5 appeared, in fact, likely to be an omega in the cursive ( $\omega$-shaped) form, apparently otherwise unattested in its own right in the Mechanism's inscriptions though it is a component of the omega-rho monogram for $̋ \rho \alpha$ ("hour") employed in the eclipse glyphs. ${ }^{13}$ Hence, lines $1-5$ can be the remains of the paragraph required before that of $6-10$.

2. To the left of the first index letter (i.e., the special symbol) reported by Freeth in line 31 , the 2016 study reported traces of three letters that, it was claimed, could be read as the first three of the four letters that Freeth's model predicts as following those of line 19. ${ }^{14}$ To account for the fourth predicted letter, it was suggested that the special symbol could have done double duty to link to two glyphs. Hence, there was no logically intervening paragraph between 11-19 and 21-31, and the total number of solar paragraphs was five, not six.

Freeth has now rebutted most of the divergences of the 2016 reconstruction from that of his 2014 paper, accepting only that there is a single index letter preceding the special symbol in line 31 , which he interprets as a second special symbol. ${ }^{15}$ As a consequence of this new reading, he offers a minor modification of his scheme for the index letter groupings while retaining the left-and-right arrangement with six paragraphs. He characterizes the modifications offered in 2016 and particularly the disagreement concerning the layout of the BPI as a "radical revision" of his scheme and "not a minor issue."16

One may hold differing views about how much the few points of disagreement between the 2016 and 2014/2019 reconstructions of the BPI and the glyph patterns matter, but they definitely deserve to be reexamined, since the paragraph structure of the BPI has bearing not only on the locations of the lunar and solar eclipse descriptions on the Back Plate but also on the details and astronomical interpretation of the theory according to which the BPI categorized solar eclipses as a function of the lunar latitude. In this paper, therefore, we offer a new critical text of the BPI based on reexamination of the CT and RTI data, and on its basis we will deduce a revision of the glyph distribution, the index lettering scheme, and the model according to which the solar groupings in the BPI were obtained. While it turns out that neither the 2016 nor the 2014/2019 discussions were entirely correct with respect to the

\footnotetext{
13 Anastasiou et al. (2016, 165 and 199).

14 Anastasiou et al. (2016, 167 and 199).

15 Freeth (2019).

16 Freeth $(2019,6)$.
} 
crucial readings of index letters in the BPI, we conclude that the layout proposed in 2016 was basically correct, that is, lines $1-5$ are the remains of the first paragraph of solar eclipse descriptions, and except for the loss of the first line and the beginnings of lines $2-5$ of this paragraph, the solar paragraphs are all extant and in correct sequence running down the right side of the plate.

\section{New Edition of the Back Plate Inscription and the Saros Dial EP Glyphs}

\subsection{Introduction to the edition}

As noted above, to the right of the Saros Dial on the back side of the Antikythera Mechanism is found what has become known in the literature on the Antikythera Mechanism as the "Back Plate Inscription," or BPI for short. It consists of a series of repeating statements, or what Freeth calls "Index Letter Groups," that describe the direction from which, or what here is called an " $\alpha \pi$ ó-statement," some plural

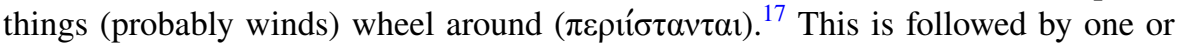
two directional statements, or what are here called " $\pi \rho$ ó $\varsigma$-statements," where these

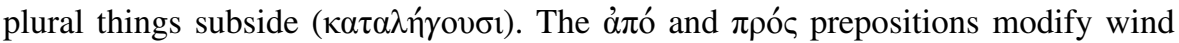
direction names and, as we shall see in a moment, these wind names clearly move counterclockwise on a standard Greek windrose, with the first lost $\alpha$ ó -statement almost certainly starting in the East. These $\alpha \pi o^{-}$and $\pi \rho o^{\prime} \varsigma$-statements are followed by an indication of the magnitude (small, medium or large) of some feminine plural things, probably solar eclipses, then an indication of the expected color (dark, fire red, or black), and finally by a line of index letters keyed to the corresponding solar eclipses on the Saros Dial. As Freeth has persuasively argued, these index letters on the BPI are not listed in alphabetical order, rather they are listed in order of decreasing mean lunar latitude, whereas the corresponding index letters on the Saros Dial start at alpha and run in alphabetical order to omega; then, they repeat this, only this time each index letter is topped with an overline to distinguish it from the nonbarred index letters. Since much of the Saros Dial is missing, the index letters on the Back Plate Inscription are an important piece of evidence to ascertain how many, and in what cells, the Saros Dial had solar eclipse glyphs.

The Back Plate Inscription itself is found on five different fragments: Fragments, A, E, F, 24, and 25. Fragment A preserves the ends of lines 1-10 and most of lines 11-20. These lines can also be read on PTM files AK45a, AK46a, AK49a, and $\mathrm{AK} 50 \mathrm{a}$, in CT and in photographs. Fragment E preserves in its interior the beginning of lines 6-9, and joins, or nearly joins, to A at line 9 ; it can mostly only be

\footnotetext{
17 As Anastasiou et al. (2016) point out, the subject of the verb $\pi \varepsilon \rho$ tí $\sigma \tau \alpha \nu \tau \alpha \mathrm{t}$ is likely to be winds rather than eclipses. The verb $\pi \varepsilon \rho$ tí $\sigma \alpha \nu \tau \alpha$ is relatively rare, but it is specifically used of winds at Aristotle Meteorologica 365a, lines 6 and 10 (the last with the preposition $\pi \rho o ́ c)$. I can find only one example of

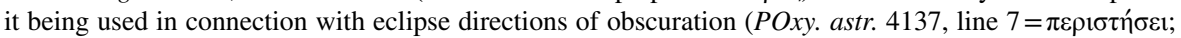
see Jones 1999, vol. 1, 87-94 and vol. 2, 16-17).
} 
read in CT, although a small piece is on PTM AK7b. Fragment 24 preserves the beginnings of lines 15-18 as mirror offsets, while Fragment 25 has mirror offsets of lines 10-17; they can be read in CT and in PTM files AK02b (24) and AK02a (25). Finally, Fragment F preserves in its interior lines 21-38 and can only be read in CT. For a full description of these, the reader is advised to consult the edition of Anastasiou et al. 2016.

\subsection{Edition and translation of the BPI}

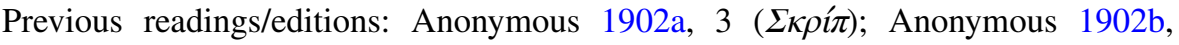
2 (NÉov 'A $\sigma \tau v$ ); Rediadis 1903a, 46 and 1903b, 45 (Svoronos); Theofanidis 1927-1929, 98-99; Price 1974, 48-51 (Stamires and Price); Freeth et al. 2006, 588 and Supplementary Information 9-10; Freeth 2014, 9 (Crowther) ${ }^{18}$; Anastasiou et al. 2016; Freeth 2019, 3.

Note that in that edition and in the previous editions in Price 1974, Freeth et al. 2006, and Freeth 2014, our lines 2-19 were numbered 1-18, and (except for Price 1974, which only had the part of the BPI in Fragment A) our lines 21-38 were numbered 19-36.

Date: fin. III-med. Ia. (ca. 100-50a.?) NON- $\Sigma$ TOIXH $\Delta \Omega$; Syllabic/Word Division

$1 \quad[\dot{\alpha} \pi$ ' 'A $\pi \eta \lambda \iota \dot{\omega} \tau o v \pi \varepsilon \rho t i ́ \sigma \tau \alpha \nu]-$

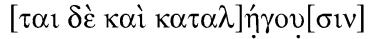
$\left.\left[\pi \rho \grave{s} .^{5} \ldots \cdot \mu\right]_{1 \kappa \rho \alpha \hat{\imath} \cdot \tau[\dot{o} \delta}^{\delta \varepsilon}\right]$ $[\chi \rho \hat{\omega} \mu \alpha \kappa \varepsilon \lambda] \alpha$ เvóv vacat

5 [vacat $\overline{\mathrm{Y}} \Gamma \overline{\mathrm{K}} \Xi] \omega$. vacat

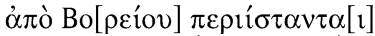

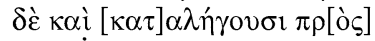
$\Lambda i ́ \beta \alpha \cdot v \mu \varepsilon^{\prime} \sigma \alpha \cdot \cdot$ ò $\delta \dot{\varepsilon} \chi \rho \hat{\omega}-$ $[\mu \alpha] \mu \alpha \mu \varepsilon^{\prime} \lambda \alpha v^{*}$ vacat

10 vac. $\overline{\mathrm{A}} \mathrm{N} \bar{\Lambda} \mathrm{B} \bar{\Phi}$. vacat

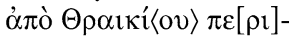

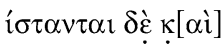
$\kappa \alpha \tau \alpha \lambda \dot{\eta} \gamma \dot{0}[v \sigma \mathrm{v}]$ $\pi \rho \grave{s}$ 'A $\pi \eta \lambda[1]-$

15

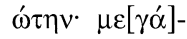
$\lambda\langle\alpha \mathrm{l}\rangle \cdot \tau \grave{o} \delta \grave{\varepsilon}$ $\chi \rho \hat{\omega} \mu \alpha$

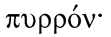
19 $\mathrm{Z} \bar{\Theta} \bar{\Sigma} \mathrm{PX}$ 20 $\bar{\Delta}[\Lambda \dot{\bar{\Xi}}]$. vacat
[From the East, they wheel] [about and also sub]sid[e] [to the - - -; s]mall-(sized); [and] the] [color (is) da]rk: $[\overline{\mathrm{Y}} \Gamma \overline{\mathrm{K}} \Xi] \omega$.

From the No[rtheast], they wheel abou[t] and also [sub]side $\mathrm{t}[\mathrm{o}]$ the Southwest; medium-(sized); and the color (is) black:

$\overline{\mathrm{A}} \mathrm{N} \bar{\Lambda} \mathrm{B} \bar{\Phi}$.

From the Northwest, they wh[eel] about and a[1so] subsid[e] to the East; 1[arge](sized); and the color (is) fiery-red: $\mathrm{Z} \overline{\mathrm{O}} \overline{\mathrm{S}} \mathrm{PX}$ $\bar{\Delta}[\Lambda \bar{\Xi}]$. vacat

18 On this publication, see Anastasiou et al. (2016: 154, n. 34). 
21

$$
\begin{aligned}
& \dot{\alpha}[\pi \mathrm{ò} \mathrm{Z} \varepsilon]-
\end{aligned}
$$

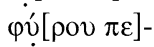

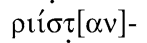

$$
\begin{aligned}
& \tau \alpha_{\imath} \delta \dot{\varepsilon}[\pi \rho o ̀ \varsigma]
\end{aligned}
$$$$
\text { Nótov } \kappa \alpha[i]
$$$$
\kappa \alpha \tau \alpha \lambda \dot{n} \gamma \circ v-
$$

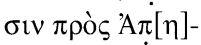

$\lambda \iota \omega^{\prime} \tau v^{*} \mu \varepsilon^{\prime}-$

$\sigma \alpha \imath \cdot \tau \grave{o} \delta \grave{\varepsilon} \chi \rho \hat{\omega}-$

$30 \mu \alpha \mu \dot{c} \lambda \alpha v^{*} v a c a t$

31 vac. $\bar{\omega} \hat{A} \bar{\Pi} K \bar{Z} \Phi$. vac.

$\dot{\alpha} \pi$ ò Nótov $\pi \varepsilon p 1-v a c$.

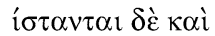

$\kappa \alpha \tau \alpha \lambda \eta \dot{\eta} \gamma \sigma v \sigma i v v$

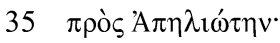

$\mu 1 \kappa \rho \alpha \hat{i} \cdot \tau \grave{c} \delta \dot{\varepsilon} \chi \rho \hat{\omega} \mu \alpha$

$\mu \varepsilon \dot{\lambda} \lambda \alpha v \cdot v a c a t$

38 vac. $\mathrm{T}_{v} \overline{\mathrm{H}}_{\iota} \Theta_{v} \overline{\mathrm{P}}$. vac.

vacat

\author{
Fr[om the We]- \\ st, [they] \\ wheel [a]- \\ bo[ut to] \\ the South an[d] \\ they sub- \\ side to the E[a]- \\ st; me- \\ dium-(sized); and the col- \\ or (is) black: \\ $\bar{\omega} \hat{A} \bar{\Pi} K \bar{Z} \Phi$. \\ From the South, they \\ wheel about and \\ also subside \\ to the East; \\ small-(sized); and the color \\ (is) black: \\ $\mathrm{T}_{v} \overline{\mathrm{H}} v \Theta_{v} \overline{\mathrm{P}}$. \\ vacat
}

\subsection{Apparatus criticus to the BPI edition}

Line 1: [ámò - - - - - - $\varepsilon \varepsilon \rho t i ́ \sigma \tau \alpha v]$, Anastasiou et al. 2016. For the restoration of 'A $\pi \eta \lambda \iota \omega ́ \tau o v$, see Commentary.

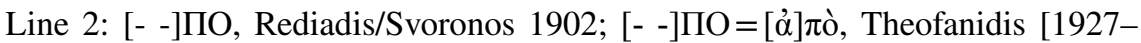
1929]; [- -]!̣!̣[- -], Price/Stamires 1974 and Freeth et al. 2006; [- - c.15 - -

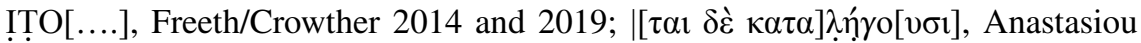
et al. It appears to be very unlikely that any part of the lambda could be present since the plate is broken away there. ${ }^{19}$ A bit of the left vertical of dotted eta is present on the CT, and the entire right vertical of dotted eta is present on the CT and in PTM AK50a. The upper horizontal of gamma does have a pronounced extension to the left of the vertical hasta (as it does elsewhere, such as at line 26 and the glyphs in cells 13 and 125), but it is too short to belong to a tau and its thickness and depth on the left end is not the same as a full letter stroke. That this is a gamma and not a tau is also shown by the fact that it is also too close to the preceding vertical hasta of dotted eta (if it were a tau, the top horizontal would need to extend well into the top of eta-see especially PTM AK50a, and compare with iota followed by tau in the line below for normal spacing of vertical stroke followed by tau). Next comes omicron, followed by what seems to be part of the

\footnotetext{
19 We have consulted a photogrammetric 3D model of A-2 as a check on the preservation of the inscribed surface in places where the PTM files and even sometimes CT can be unclear.
} 
lower tip of the vertical of dotted upsilon, high in the line where it should be, on PTM AK50a and photographs. The inscriber seems to use the nu-movable when there is space; $c f$. lines 26 and 34 .

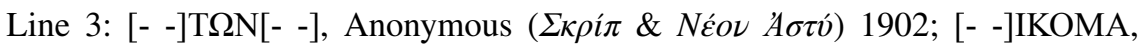
Rediadis/Svoronos 1902 and Theofanidis [1927-1929]; [- -]IKỌ LIT, Price/Stamires 1974 and Freeth et al. 2006; [- - c.12_-]IKPAIT! [...], Freeth/Crowther 2014

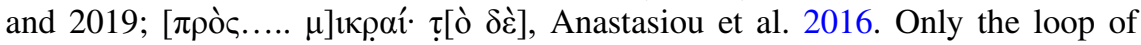
rho is clear, but it is broken at the bottom so epigraphically speaking B cannot be ruled out. The tau at the end of the line is clear, particularly in PTM AK50a. At the beginning of the line, the restorations $[\pi \rho$ ò $\varsigma \Lambda \hat{i} \beta \alpha \cdot V \mu] 1 \kappa \rho \alpha i \cdot \tau[\grave{o}]$, or $[\pi \rho$ ò

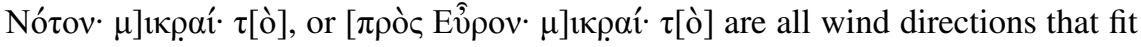
the likely spacing and directional requirements.

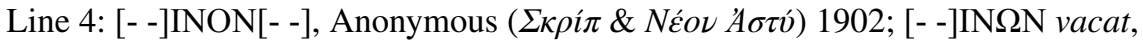

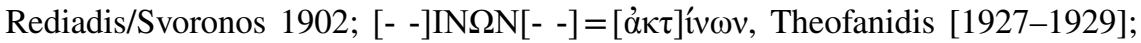

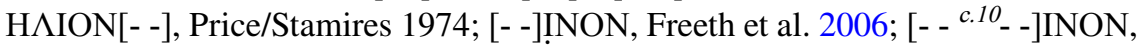

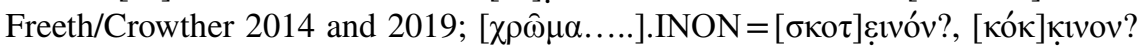

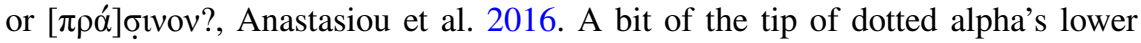
diagonal is visible in the CT and is clear on PTM AK50a. Epigraphically speaking, it can belong only to a $\mathrm{A}, \Delta, \mathrm{E}, \mathrm{Z}, \mathrm{K}, \Lambda, \mathrm{M}, \Xi, \Sigma, \mathrm{X}$, or possibly $\Omega$. A dark color makes more sense in this context; hence, $[\sigma \kappa \sigma \tau] \varepsilon ̣ v o ́ v$ or $[\kappa \varepsilon \lambda] \alpha$ ivóv seem

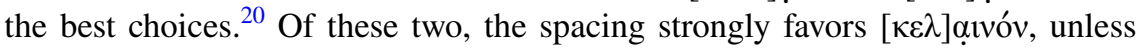
the line was not indented.

Line 5: [- -]O, Freeth et al. 2006 (with material from Fragment E mistakenly placed before this at the beginning of the line); [- $\left.{ }^{c .10}{ }_{-}\right] \mathrm{O}$, Freeth/Crowther 2014 and 2019; [- - $\omega$ Anastasiou et al. 2016. The loop is much larger and flares out to the right, nor does it connect at the top, precluding any other round letter such as omicron and phi. The same letter, $\omega$, with the exact same flaring right loop, is found below at the beginning of line 31, making the reading assured. For other reasons apart from epigraphical considerations as to why $\mathrm{O}$ is also unlikely as a restoration, see Commentary.

Line 6: [- -] $\Xi \Omega[\ldots] \mathrm{TAN}$, Rediadis/Svoronos 1902; [- - $] \Xi \Omega[\ldots] \mathrm{TAN}[]=.[--] \xi \omega$ [.. ó] $\tau \alpha v$ [.], Theofanidis [1927-1929]; [- - ] $\Xi \Omega[-$-]NTAN, Price/Stamires 1974; AПOXִ $[-] \Xi \Omega[-~-] N T A N[-]$, Freeth et al. 2006 (the first 5 letters mistakenly

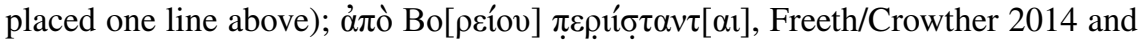

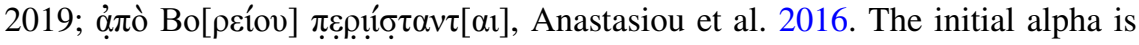

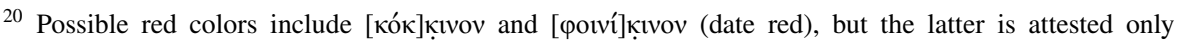

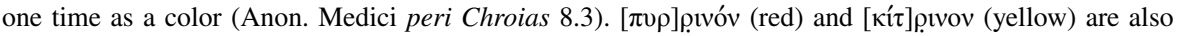
excludable, as the visible trace before the extent iota would be too crowded to fit a rho, which also does not fit the visible trace. [ $\pi \rho \alpha$ ] $\operatorname{cov}_{\mathrm{t} o v}$ is the only other color known to us that is consistent with the trace, but the color green, while used to describe the color of an eclipse, seems much less likely.
} 
clear. The dotted pi is blurry, but the two vertical hastae seem present. All but the top of epsilon is clear in the CT data and on PTM AK46a. The entire rho is faint, but visible in PTM AK50a. The vertical of the first iota is present on the CT and most of the left side of the sigma (the right side is lost in a large crack). At the end of the line, the left half of tau is present on the CT and a part of the upper right horizontal in photographs, while the lower left diagonal of dotted alpha is also visible in photographs.

Line 7: [- -]ОП, Rediadis/Svoronos 1902 and Theofanidis [1927-1929]; [- -]/IП[- - ]

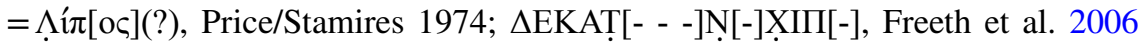
(the first 5 letters mistakenly placed one line above); $\delta \dot{\varepsilon} \kappa \alpha \grave{~}[\kappa \alpha \tau] \alpha \lambda \eta ́ n o v \sigma ı ~ \pi \rho[\grave{o} \varsigma]$,

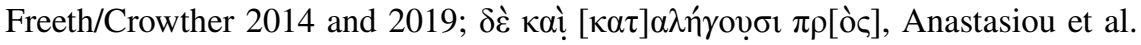
2016. The dotted iota is complete, but it is along a break to the right that epigraphically speaking could belong to other letters. The upsilon is faint on the CT, but it is completely visible in PTM AK50a.

Line 8: $\Lambda$ IBA[- - ], Freeth et al. 2006 (with misplacement of the initial letters from Fragment $\mathrm{E}$ one line above); $\Lambda$ í $\beta \alpha[..] \Omega$.E. $\mathrm{AI} \cdot \tau[\mathrm{o} \delta \grave{\varepsilon}] \chi \rho \hat{\omega} \mid$, Freeth/Crowther

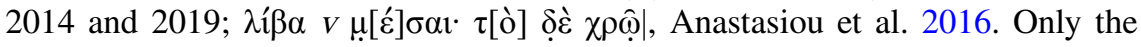
lower tip of the left diagonal of dotted mu is present on Fragment E. This is followed by the middle horizontal of epsilon that is visible on the CT, while the upper horizontal and left vertical on visible on PTM AK50a. The sigma is a bit distorted, only a part of the upper branch is missing, making the reading assured. The omicron is faint (a part of its loop is also visible on PTM AK50a), but visible. A bit of the lower left corner of delta is present on the CT and a piece of the right diagonal on PTM AK50a. At the end of the line, the left half of omega is preserved on the CT, and the right half is visible on PTM AK50a, making the reading assured.

Line 9: $\Lambda$ [- -]Ṃ̂. - - ]Ṇ[- -], Freeth et al. 2006 (with misplacement of the initial letters from Fragment E one line above); | $\mu \alpha \mu \mu_{c}^{\prime} \lambda \alpha v$, Freeth/Crowther 2014 and 2019; $\mid \llbracket \mu \alpha \rrbracket \mu \alpha \mu \varepsilon \dot{\varepsilon} \lambda \alpha v$, Anastasiou et al. 2016. At the beginning of the line, the faint traces of MA are visible, apparently erased or only lightly incised before it was decided to move them over. Previous editors have dotted the initial mu of

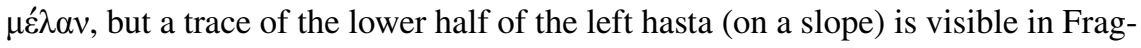
ment E, and the entire right half is visible in Fragment A; thus, it can be no other letter. This also indicates where Fragment E joins, or nearly joins, to Fragment A.

Line 10: N $\bar{\Lambda} \mathrm{B} \Phi \bar{\Phi}$, Freeth/Crowther 2014 and 2019; AvNv.vḄ 2016. The alpha with crossbar and overline is clear in CT (see Fig. 6). The space between alpha and nu, as well as those between the other letters in the line, is of just normal breadth. There is a large crack at the bottom of dotted lambda, which theoretically means delta cannot be ruled out. Above it, there seems to be a piece of the overline that intersects with the lower right tip of the lambda in the line above. The dotted beta seems mostly there, although the bottom is partly missing 
owing to the large crack. The phi at the end of the line is clear on the CT. Its vertical hasta extends all the way up next to the right edge of the final nu in the line above, and the overline appears to be there, next to the nu.

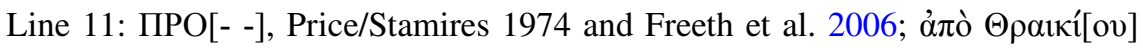

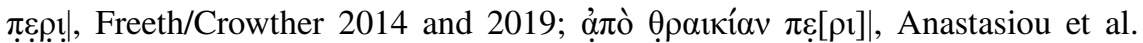

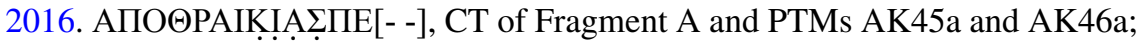
[- -] and it is also clear that at the end of the offset text of Fragment 25 there is a sigma followed by a final vertical stroke, the latter which belongs to the initial stroke of the $\Pi$. The lower left corner and top of the epsilon are present on the CT data and most of the entire letter present on PTM AK46a.

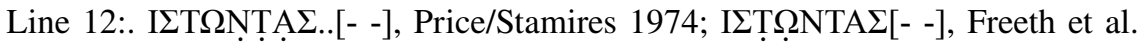

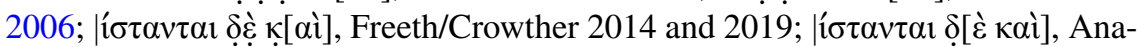
stasiou et al. 2016. The lower left corner of delta is especially present on the CT data of Fragment 25, the outline of the rest on the CT of Fragment A, and the apex on PTMs AK45a and AK46a (it can be no other letter). Parts of the vertical hasta and upper horizontal of dotted epsilon are visible on the CT of Fragment A and on the PTMs AK45a and AK46a. There appears to be a piece of the lower hasta of kappa in PTMs AK45a, AK46a, and photographs.

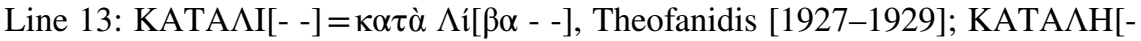

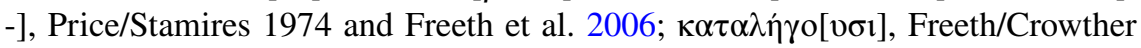

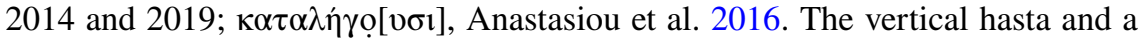
part of the horizontal hasta of dotted gamma are there, but epigraphically speaking they could belong to pi. About two-thirds of the loop of dotted omicron is visible in the CT and in the PTMs (AK45a, AK46a, AK50a) right next to a crack near the right edge; epigraphically speaking, it could also be a theta.

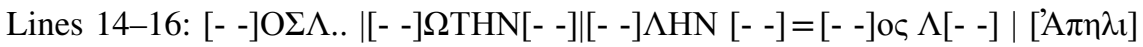

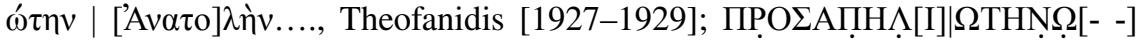

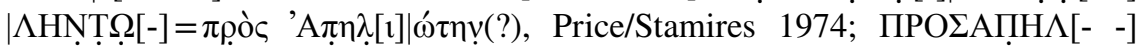

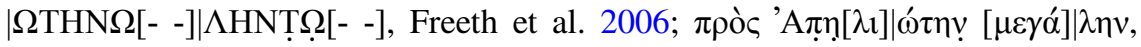

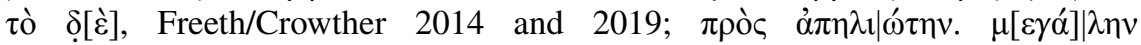

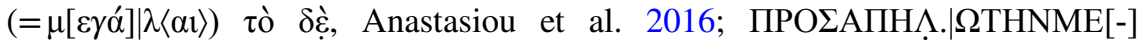
$\mid \Lambda \mathrm{HNTO} \Delta .[-]$, composite evidence. In line 14, the second pi is entirely present on the mirror offsets of Fragment 25. The left vertical of eta is very clear there too, but Fragment 25 ends at this point. However, a piece of the crossbar of eta is clear in photographs (typically located low on the vertical) as well as the right vertical, making the reading assured. Much of the lambda is present on PTMs AK45a, AK46a, and photographs, but there is damage through the middle, and epigraphically speaking, it could belong to an alpha. In line 15 , the nu and mu are clear on the CT data of Fragment 25. This is followed by the lower left corner of epsilon in a photograph. In line 16 , the letters $\Lambda$ HNTO $\Delta$. (with the final trace 
being the lower left corner of dotted epsilon) are clear on the PTMs, the CT data of the Fragment 25 mirror image, and the photographs. Anastasiou et al.'s statement that the accusative singular $\mu\left[\varepsilon \gamma \alpha^{\alpha}\right] \mid \lambda \eta \nu$ is a mistake for $\mu\left[\varepsilon \gamma \alpha^{\prime}\right] \mid \lambda\langle\alpha 1\rangle$ seems inevitable.

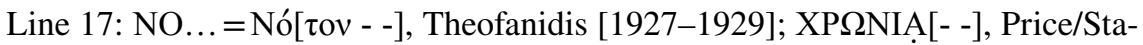
mires 1974 and Freeth et al. 2006; $\chi \rho \hat{\omega} \mu \alpha$, Freeth/Crowther 2014/2019 and Anastasiou et al. 2016.

Line 18: ПY $[\Gamma] \mathrm{O}[\Sigma]=’ \operatorname{ló} \mid \pi v[\gamma] \mathrm{ọ}[\varsigma](?)$, Price/Stamires 1974; ПY[-]Ọ[-], Freeth

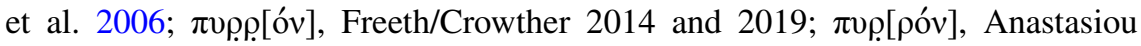
et al. 2016. The rhos are faint but visible on the CT crowded against each other (the entire vertical hasta and a bit of the lower loop of the first rho are visible on the PTMs AK45a and 46a). Most of the omicron and nu are visible in PTMs AK45a and AK46a and parts on the CT.

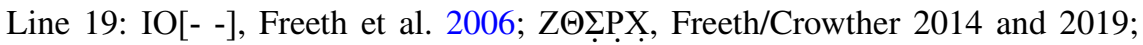
$\mathrm{Z} \bar{\Theta} \Sigma$.X. Anastasiou et al. 2016. While the center of the theta is missing, the size of the letter means it cannot be an omicron, which is consistently smaller. The overline is also very evident. The top horizontal and upper left corner of sigma are preserved on the CT (with no overline evident) and a bit of the lower horizontal, followed by the faint outline of the loop of rho, followed by the chi (the chi is very clear in photographs).

Line 20: This line is ignored by all previous editors (first read by A. Jones). There is evidence for the delta in the CT, and it and its overline are also evident in PTMs AK45a and AK46a, particularly with Spectacular Enhancement (see Fig. 7). For more on this line, see Commentary and Analysis sections.

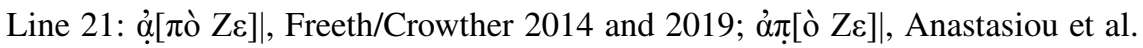
2016. The lower tip of the right diagonal of dotted alpha is present.

Line 22: $\Phi[--]$, Freeth et al. 2006; $\varphi \underline{u}[\rho o v ~ \pi \varepsilon]$, Freeth/Crowther 2014/2019 and Anastasiou et al. 2016. A trace of the tips of the upper left diagonal and lower vertical of dotted upsilon are visible.

Line 23: PII $\Sigma[--]$, Freeth et al. 2006; $|\rho t i ́ \sigma \tau[\alpha v]|$, Freeth/Crowther 2014/2019 and Anastasiou et al. 2016. The lower tip of the dotted tau is visible along with a bit of the left tip of the upper horizontal.

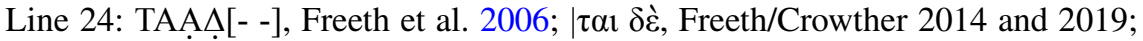
$\mid \tau \alpha \iota$ $\delta \grave{\varepsilon}[\pi \rho \grave{c} \varsigma]$, Anastasiou et al. 2016. 
Line 25: NOTON, Freeth et al. 2006; Nótov $\kappa[\alpha i]$, Freeth/Crowther 2014 and 2019; Nótov $\kappa[\alpha i]$, Anastasiou et al. 2016. The kappa is entirely there and the lower left diagonal and a piece of the crossbar of alpha.

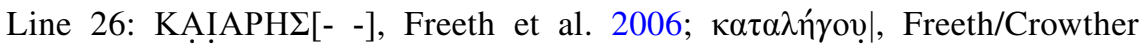
2014/2019 and Anastasiou et al. 2016. The upper left tip of the left diagonal and the lower tip of the vertical of dotted upsilon are visible.

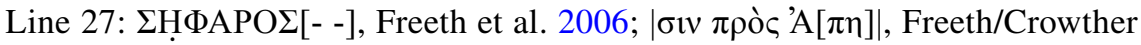
2014/2019 and Anastasiou et al. 2016. The left vertical and a bit of the upper left corner of dotted pi are visible at the break; it could also be a gamma.

Line 28: $\Lambda$ ENTHNK [- - ], Freeth et al. 2006; $\mid \lambda \iota \omega ́ \tau \eta \nu \mu[\varepsilon]$ ], Freeth/Crowther

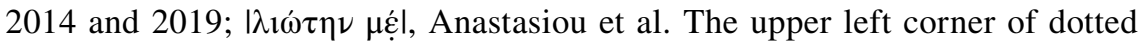
epsilon and some of the upper horizontal are present; it could also be gamma.

Line 29: $\Sigma A \oplus Y \Lambda A \Xi A \Sigma[--]$, Freeth et al. 2006; $\mid \sigma \alpha \imath^{\cdot} \tau$ cò $\delta \grave{\varepsilon} \chi \rho \hat{\omega} \mid$, Freeth/ Crowther 2014 and 2019; $\mid \sigma \alpha \iota^{\cdot} \tau$ ò $\delta \dot{\varepsilon} \chi \rho \hat{\varphi} \mid$, Anastasiou et al. 2016. The final letter can be nothing other than omega.

Line 30: I $\Lambda \mathrm{AME} \Lambda \mathrm{AN}$, Freeth et al. 2006; $\mid \mu \alpha \mu \varepsilon \dot{ } \lambda \alpha \nu$, Freeth/Crowther 2014/2019 and Anastasiou et al.

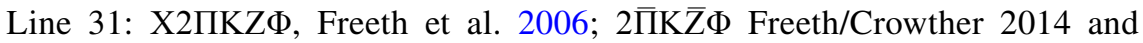

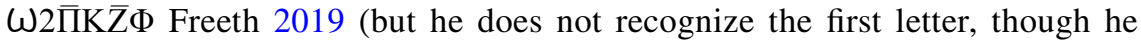
traces it correctly, is actually a cursive omega);.$\Lambda \bar{\Xi} \hat{A} \bar{\Pi} K \bar{Z} \Phi$, Anastasiou et al. 2016. There is only one letter before the $\hat{\mathrm{A}}$, which has the form 2 and is a "hooked alpha" (i.e., there are not traces of 3 letters here), and that letter is clearly $\bar{\omega}$ with some $x$-shaped damage after it (the overline is faint, but visible). The overline over pi is very evident, and there also seems to be a faint overline over the Z. For more on the cursive omega and hooked alpha, see Commentary.

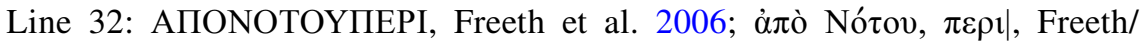
Crowther 2014/2019 and Anastasiou et al.

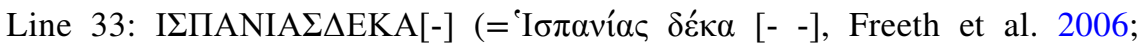

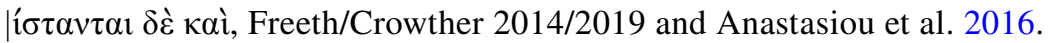

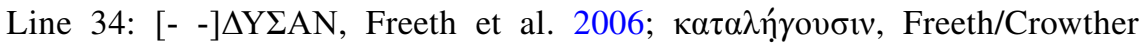
2014/2019 and Anastasiou et al. 2016.

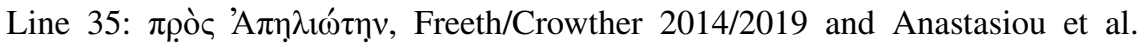
2016. 


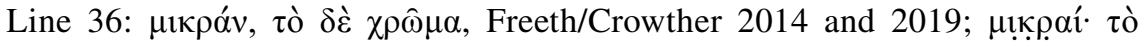
$\delta \grave{\varepsilon} \chi \rho \hat{\omega} \mu \alpha$, Anastasiou et al. 2016. The loop and vertical of rho are somewhat indistinct, but visible. The crossbar of the final alpha is faint, but there.

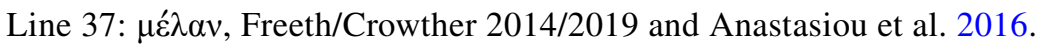

Line 38: $v \mathrm{~T} v \overline{\mathrm{H}} v \Theta v \overline{\mathrm{P}} v \bar{\Psi}$, Freeth/Crowther 2014/2019 and Anastasiou et al. 2016. The overlines over eta and rho are clear. There does not seem to be any trace of a letter after the rho.

\subsection{Edition and translation of the extant eclipse possibility glyphs}

\begin{tabular}{|c|c|c|}
\hline Cell 8 & 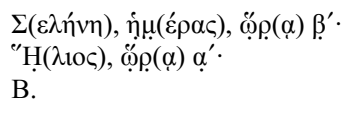 & $\begin{array}{l}\text { Moon, daytime, at the } 2 \text { nd hour; } \\
\text { Sun, at } 1 \text { st hour; } \\
\text { B. }\end{array}$ \\
\hline Cell 13 & $\begin{array}{l}{ }^{\circ} \mathrm{H}(\lambda \mathrm{loc}), \mathrm{vac} . \\
\omega \rho(\alpha) \alpha^{\prime} \\
\Gamma .\end{array}$ & $\begin{array}{l}\text { Sun, } \\
\text { at the 1st hour; } \\
\Gamma \text {. }\end{array}$ \\
\hline Cell 20 & $\begin{array}{l}\Sigma(\varepsilon \lambda \eta \dot{n} v \eta), \text { vac. } \\
\dddot{\omega} \rho(\alpha) \varsigma^{\prime} . \\
\text { E. }\end{array}$ & $\begin{array}{l}\text { Moon, } \\
\text { at the 6th hour; } \\
\text { E. }\end{array}$ \\
\hline Cell 25 & $\begin{array}{l}\text { "H }\left(\lambda \lambda_{10 \varsigma}\right), \text { vac. } \\
\omega \rho(\alpha) \varsigma^{\prime} . \\
Z .\end{array}$ & $\begin{array}{l}\text { Sun, } \\
\text { at the 6th hour; } \\
\mathrm{Z} \text {. }\end{array}$ \\
\hline Cell 26 & $\begin{array}{l}\Sigma\left(\varepsilon \lambda \eta \eta^{\prime} \eta\right), \dot{\eta} \mu(\dot{\varepsilon} \rho \alpha \varsigma), \\
\dddot{\omega} \rho(\alpha) \zeta^{\prime} \cdot \\
H .\end{array}$ & $\begin{array}{l}\text { Moon, daytime, } \\
\text { at the 7th hour; } \\
\text { H. }\end{array}$ \\
\hline Cell 61 & $\begin{array}{l}\sum\left(\varepsilon \lambda \eta^{\prime} \eta \eta\right),[--?] \\
{[\check{\omega} \rho(\alpha)-']} \\
{[O] .}\end{array}$ & $\begin{array}{l}\text { Moon, [- -?], } \\
\text { [at the - hour]; } \\
\text { [O]. }\end{array}$ \\
\hline Cell 67 & $\begin{array}{l}\sum\left(\varepsilon \lambda \eta \eta_{v \eta}\right), v \underline{v}(\kappa \tau o ́ c) \\
\dddot{\omega} \rho(\alpha) \eta^{\prime} \cdot \\
\Pi .\end{array}$ & $\begin{array}{l}\text { Moon, nighttime, } \\
\text { at the 8th hour; } \\
\Pi \text { П. }\end{array}$ \\
\hline Cell 72 & 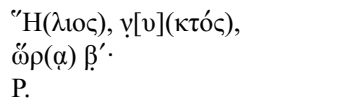 & $\begin{array}{l}\text { Sun, n[ighttime], } \\
\text { at the 2nd hour; } \\
\text { P. }\end{array}$ \\
\hline Cells 73-74 & See apparatus criticus. & \\
\hline Cell 78 & 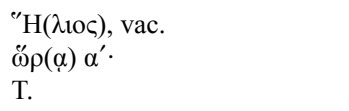 & $\begin{array}{l}\text { Sun, } \\
\text { at the 1st hour; } \\
\text { T. }\end{array}$ \\
\hline Cell 79 & $\begin{array}{l}\Sigma\left(\varepsilon \lambda \eta \eta^{\prime} \eta\right), \dot{\eta} \mu(\dot{\varepsilon} \rho \alpha \varsigma), \\
\omega \rho(\alpha) \iota^{\prime} \cdot \\
Y .\end{array}$ & $\begin{array}{l}\text { Moon, daytime, } \\
\text { at the 10th hour; } \\
\text { Y. }\end{array}$ \\
\hline Cell 114 & 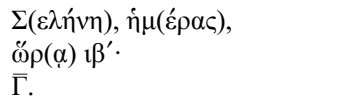 & $\begin{array}{l}\text { Moon, daytime, } \\
\text { at the } 12 \text { th hour; } \\
\bar{\Gamma} \text {. }\end{array}$ \\
\hline
\end{tabular}




\begin{tabular}{|c|c|c|}
\hline Cell 119 & 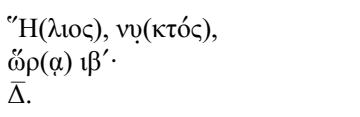 & $\begin{array}{l}\text { Sun, nighttime, } \\
\text { at the } 12 \text { th hour; } \\
\bar{\Delta} \text {. }\end{array}$ \\
\hline Cell 120 & 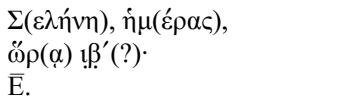 & $\begin{array}{l}\text { Moon, daytime, } \\
\text { at the } 12 \operatorname{th}(?) \text { hour; } \\
\overline{\mathrm{E}} \text {. }\end{array}$ \\
\hline Cell 125 & 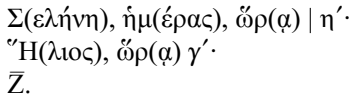 & $\begin{array}{l}\text { Moon, daytime, at the 9th hour; } \\
\text { Sun, at the 3rd hour; } \\
\bar{Z} \text {. }\end{array}$ \\
\hline Cell 131 & 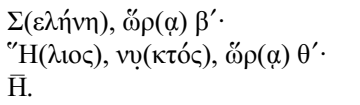 & $\begin{array}{l}\text { Moon, at the } 2 \text { nd hour; } \\
\text { Sun, nighttime, at the } 9 \text { th hour; } \\
\overline{\mathrm{H}} \text {. }\end{array}$ \\
\hline Cell 137 & 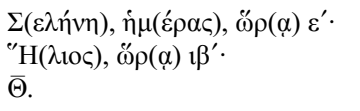 & $\begin{array}{l}\text { Moon, daytime, at the } 5 \text { th hour; } \\
\text { Sun, at the } 12 \text { th hour; } \\
\bar{\Theta} \text {. }\end{array}$ \\
\hline Cell 172 & $\begin{array}{l}\sum\left(\varepsilon \lambda \eta^{\prime} v \eta\right), \% \rho(\alpha) \varsigma^{\prime} \\
" H(\lambda 10 \varsigma), \omega \rho(\alpha) i \beta^{\prime} \\
\bar{\Pi} .\end{array}$ & $\begin{array}{l}\text { Moon, at the 6th hour; } \\
\text { Sun, at the } 12 \text { th hour; } \\
\bar{\Pi} .\end{array}$ \\
\hline Cell 178 & $\begin{array}{l}\sum(\varepsilon \lambda \eta \dot{n} v \eta), \dddot{\rho} \rho(\alpha) \theta^{\prime} . \\
{ }^{\prime} \mathrm{H}(\lambda 10 \varsigma), \omega \rho(\alpha) \theta^{\prime} . \\
\overline{\mathrm{P}} .\end{array}$ & $\begin{array}{l}\text { Moon, at the 9th hour; } \\
\text { Sun, at the 9th hour; } \\
\overline{\mathrm{P}} \text {. }\end{array}$ \\
\hline Cell 184 & 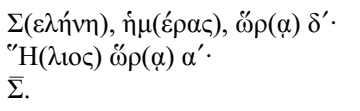 & $\begin{array}{l}\text { Moon, daytime, at the } 4 \text { th hour; } \\
\text { Sun, at the } 1 \text { st hour; } \\
\bar{\Sigma} \text {. }\end{array}$ \\
\hline Cell 190 & $\begin{array}{l}\Sigma\left(\varepsilon \lambda \eta \eta^{\prime} \eta\right), \dot{\eta} \mu(\varepsilon \dot{\varepsilon} \rho \alpha), \\
\dddot{\omega} \rho(\alpha) \theta^{\prime} \cdot \\
\overline{\mathrm{T}} .\end{array}$ & $\begin{array}{l}\text { Moon, daytime, } \\
\text { at the 9th hour; } \\
\overline{\mathrm{T}} \text {. }\end{array}$ \\
\hline
\end{tabular}

\subsection{Apparatus criticus to the edition of the glyphs}

Cell 8: $\Sigma(\varepsilon \lambda \eta ́ v \eta)$. . . | B (lunar and probably also solar glyph) Anastasiou et al. 2016. In the drawing above (Fig. 1), the letters or letter strokes in blue are very faint but seem to be there. In line 2, the final dotted alpha could also conceivably be a delta.

Cell 13: [- - ]| [-] \& A | [- -], Price/Stamires 1974, 48; “H( $\left.\lambda_{10 \varsigma}\right)|\dddot{\omega} \rho(\alpha) \bar{\Lambda}|$, Freeth

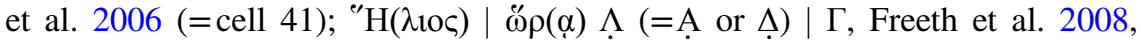
Freeth/Crowther 2014 and Freeth 2019; line $2={ }^{\circ \prime} \mathrm{H}\left(\lambda_{10}\right.$ (o) $) \omega(\alpha) \alpha^{\prime}$, Anastasiou et al. 2016. In line 2, the crossbar of alpha is very evident.

Cell 20: $\Sigma(\varepsilon \lambda \eta \dot{v \eta}) \mathrm{M}\left|\dddot{\omega} \rho(\alpha) \varsigma^{\prime}\right| \mathrm{E}$ (=cell 48), Freeth et al. 2006; $\Sigma(\varepsilon \lambda \eta \dot{v \eta})$ $\left|\omega \varrho \rho(\alpha) \varsigma^{\prime}\right|$ E, Freeth et al. 2008, Freeth/Crowther 2014 and Freeth 2019; line $1=\Sigma(\varepsilon \lambda \eta ́ v \eta)$ [-], Anastasiou et al. 2016. In line 1, after the sigma in some slices it appears that there may be a nu of the monogram $v 0(\kappa \tau o ́ c)$, but these slices are not at the level of the plate, where the space appears to be empty.

Cell 25: "H( $\left.\lambda_{1 \circ \varsigma}\right),\left|\dddot{\rho} \rho(\alpha) \varsigma^{\prime}\right|$ Z, Freeth et al. 2006 (=cell 53), Freeth et al. 2008, Freeth/Crowther 2014, Freeth 2019, and Anastasiou et al. 2016.

Cell 26: $\Sigma(\varepsilon \lambda \eta ́ v \eta), \dot{\eta} \mu(\varepsilon \rho \alpha \varsigma) ~ \% \rho(\alpha) \zeta^{\prime} \mid$ H, Freeth et al.2006 (=cell 54) and 2008, Freeth/Crowther 2014, Freeth 2019 and Anastasiou et al. 2016. 
Cell 61: The left half of the sigma in line one is very clear on Fragment E, while the rest of the cell is lost.

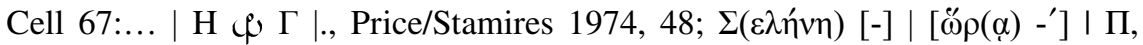
Freeth et al. 2008, Freeth/Crowther 2014 and Freeth 2019; line $2=\% \rho(\alpha) \eta^{\prime}$, Anastasiou et al. 2016. In line 1, there is a faint but visible sigma, nu, and the lower vertical hasta of upsilon above it in ligature. In line 2, the right half of the monogram $\dddot{\rho}(\alpha)$ is quite visible, as is the eta.

Cell 72: " $\mathrm{H}(\lambda \mathrm{loc})[-]|.+| .$, Freeth et al. 2006 (=cell 100); $\left.{ }^{\circ} \mathrm{H}(\lambda \mathrm{loc})[-] \mid\right)+\mid$ P, Freeth

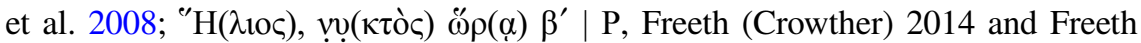
2019; line $2=\oiiint_{\rho} \rho(\alpha) \beta^{\prime}$ or $\varepsilon^{\prime}$ or [1] $\beta^{\prime}$, Anastasiou et al. (2016). The beta in line two seems reasonably certain, although it could possibly be epsilon. The spacing between the monogram of $\dddot{\rho}(\alpha)$ and the beta seems too narrow to fit an iota.

Cells 73-74: As Anastasiou et al. 2016, 160-161 point out, a piece of Fragment A broke off before Price's time and was reattached to Fragment A so that part of its preserved first turn of the Saros Dial was contiguous with cell 13 and part of its preserved second turn was contiguous with cell 72, when in fact the two fragments do not actually join. Based on earlier photographic evidence, there should be a gap of about one cell between them (the gap is that which had cell 14 and most of cell 73, both which should contain glyphs in all reconstruction schemes). Here we report that it appears that the line dividing cells 73 and 74 seems to be preserved, but no certain letters can be made out in cell 73 .

Cell 78: " $\mathrm{H}\left(\lambda_{10 \varsigma}\right)\left|\dddot{\omega} \rho(\alpha) . \alpha^{\prime}\right| \mathrm{T}$, Freeth et al. 2006 (=cell 106); ${ }^{\prime} \mathrm{H}\left(\lambda_{10 \varsigma}\right) \mid \dddot{\omega} \rho(\alpha)$ $v v(\kappa \tau$ ò $) \alpha^{\prime} \mid$ T, Freeth et al. 2008; line $2=\% \rho(\alpha) \alpha^{\prime}$ Freeth/Crowther 2014, Freeth 2019 and Anastasiou et al. (2016). In line 2, there is damage in the form of a vertical hasta between $\omega \rho(\alpha)$ and $\alpha^{\prime}$, which conceivably could make the numeral $1 \alpha^{\prime}$, but it is not spaced correctly, it does not have uniform thickness (it is much thicker at the top), it is slightly slanted, and it appears to be damage.

Cell 79: $\Sigma(\varepsilon \lambda \eta ́ v \eta), \dot{\eta} \mu\left(\varepsilon^{\prime} \rho \alpha \varsigma\right)\left|\dddot{\rho} \rho(\alpha) \kappa^{\prime}\right|$ Y, Freeth et al. 2006 (=cell 107); $\Sigma\left(\varepsilon \lambda \eta^{\prime} \sim \eta\right), \dot{\eta} \mu(\varepsilon \rho \alpha \varsigma)\left|\dddot{\omega} \rho(\alpha) \imath^{\prime}\right|$ Y, Freeth et al. 2008, Freeth/Crowther 2014, Freeth 2019, and Anastasiou et al. 2016.

Cell 114: $\Sigma(\varepsilon \lambda \eta ́ v \eta), \dot{\eta} \mu\left(\varepsilon^{\prime} \rho \alpha \varsigma\right)\left|\dddot{\omega} \rho(\alpha) ! \beta^{\prime}\right| \bar{\Gamma}$, Freeth et al. 2006 (=cell 142), Freeth et al. 2008, Freeth/Crowther 2014 and Freeth 2019; line $2=\omega{ }^{\prime}(\alpha) 1 \beta^{\prime} \mid \bar{\Gamma}$, Anastasiou et al. 2016. In line 2, the iota is clear, and in line 3 the gamma is clear.

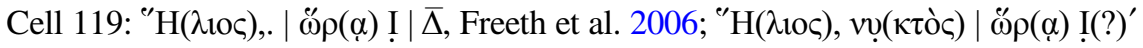
$\mid \bar{\Delta}$, Freeth et al. 2008 and Freeth/Crowther 2014 and Freeth 2019; line $1={ }^{\prime \prime} \mathrm{H}\left(\lambda_{1} \circ c_{)}\right)$,

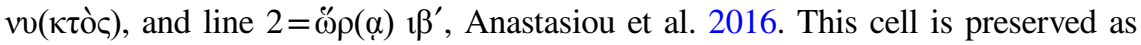
offset text that can be read on CT; parts are also visible on PTM AK7b. In line 1, the upsilon is clear. In line 2, a piece of the lower serif of the vertical hasta of beta is evident on Fragment E, while the rest of beta is clear on Fragment A.

Cell 120: $\Sigma\left(\varepsilon \lambda \eta^{\prime} v \eta\right), \dot{\eta} \mu(\varepsilon \rho \alpha \varsigma)\left|\omega ̋ \rho(\alpha) H^{\prime}(?)\right| \bar{E}$, Freeth et al. 2008; lines 2-3=ఋ $\rho(\alpha)$ IB $^{\prime}(?) \mid \overline{\mathrm{E}}$, Freeth/Crowther 2014; line 2=\% $\rho(\alpha)$ I[-], Anastasiou 
et al. 2016. At the end of line 2, the clear outline of the letters IB is visible in some CT slices, but given the nature of the CT data, they are not very uncertain. In line 3, the epsilon with overline is a bit blurry, but it can be read in its entirety.

Cell 125: $\Sigma(\varepsilon \lambda \eta ́ v \eta)], . .{ }^{\circ} \mathrm{H}(\lambda 10 \varsigma), \dddot{\rho} \rho(\alpha) \gamma^{\prime} \mid$. , Freeth et al. 2006 (=cell 153); $\left[\Sigma\left(\varepsilon \lambda \eta^{\prime} v \eta\right)\right],\left.\dot{\eta} \mu\left(\varepsilon_{\rho}^{\prime} \rho \alpha\right) \dddot{\omega} \rho(\alpha) \eta^{\prime}\right|^{\prime \prime} \mathrm{H}(\lambda 10 \varsigma), \omega \rho(\alpha) \gamma^{\prime} \mid \bar{Z}$, Freeth et al. 2008; line

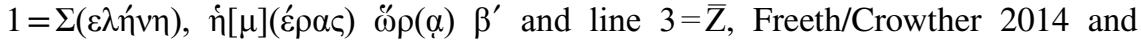

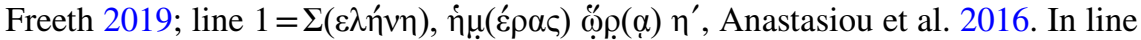
1 , the eta, which is inscribed in cell 126 , is clear on PTM AK48a and photographs. In line 3, the entire zeta is clear in photographs.

Cell 131: $\Sigma(\varepsilon \lambda \eta ́ v \eta) . . \mid{ }^{~} \mathrm{H}\left(\lambda_{10 \varsigma}\right)$,. $\dddot{\rho} \rho(\alpha) \theta^{\prime} \mid \overline{\mathrm{H}}$, Freeth et al. 2006 (=cell 159);

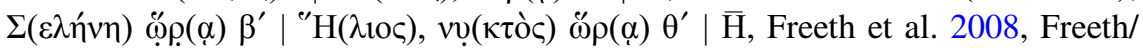
Crowther 2014, Anastasiou et al. 2016 and Freeth 2019.

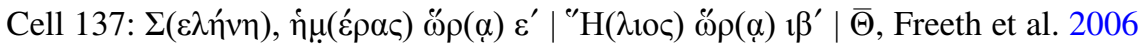

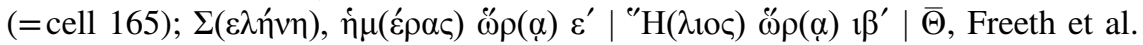
2008, Freeth/Crowther 2014, Anastasiou et al. 2016 and Freeth 2019.

Cell 172: $\Sigma(\varepsilon \lambda \eta ́ v \eta), . . \mid{ }^{\circ} \mathrm{H}(\lambda \operatorname{loc})$, $̋(\alpha)$. | П, Freeth et al. 2006 (=cell 200);

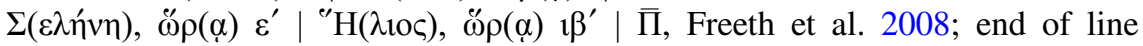
$1=\omega \rho(\alpha) \varsigma^{\prime}$, Freeth/Crowther 2014, Anastasiou et al. 2016 and Freeth 2019. The stigma at the end of line is clear.

Cell 178: $\Sigma \mathfrak{p} \Theta|\mathrm{H} \mathfrak{p} \mathrm{O}| \Gamma$, Price/Stamires 1974, 48; $\Sigma(\varepsilon \lambda \eta ́ v \eta), \dddot{\rho} \rho(\alpha) \theta^{\prime} \mid$ ${ }^{\circ} \mathrm{H}\left(\lambda\right.$ toc), $\omega_{\rho}(\alpha) \theta^{\prime} \mid \overline{\mathrm{P}}$, Freeth et al. 2006 (=cell 206) and 2008, Freeth/Crowther 2014, Anastasiou et al. 2016 and Freeth 2019.

Cell 184: $\Sigma$ YI $\Sigma \mid$ | ФA, Price/Stamires 1974, 48; $\Sigma(\varepsilon \lambda \eta ́ v \eta), \dot{\eta} \mu(\varepsilon \rho \alpha \varsigma) \dddot{\rho} \rho(\alpha) \delta^{\prime} \mid$

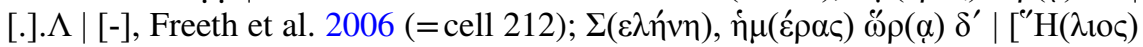
$\dddot{\omega} \rho(\alpha) \alpha^{\prime} \mid[\bar{\Sigma}]$, Freeth et al. 2008, Freeth/Crowther 2014 and Freeth 2019; lines $2-3={ }^{\prime \prime} \mathrm{H}(\lambda \mathrm{lo \varsigma}) \dddot{\omega} \rho(\alpha) \alpha^{\prime} \mid \bar{\Sigma}$, Anastasiou et al. 2016. The letters are all clear in photographs, except for part of the lower left angle of the index letter sigma.

Cell 190: $\Sigma(\varepsilon \lambda \eta ́ v \eta), \dot{\eta} \mu\left(\varepsilon^{\prime} \rho \alpha \varsigma\right)\left|\dddot{\rho} \rho(\alpha) \theta^{\prime}\right| \bar{T}$, Freeth et al. 2006 (=cell 218), Freeth et al. 2008, Freeth/Crowther 2014, Anastasiou et al. 2016 and Freeth 2019.

\section{Commentary on the editions}

This commentary addresses three issues: (1) the paleography of the inscriptions, with particular attention to the use of cursive omegas and a symbol that we argue is a hooked alpha as index letters; (2) the restoration of BPI 1-5 as a paragraph of eclipse descriptions; and (3) Freeth's 2019 defense of his 2014 reconstruction of the layout of the BPI.

\subsection{The paleography of the eclipse inscriptions}

The inscriber observes word or syllabic division at the ends of lines and the lettering is extremely small (1.5-3.0 mm.) and elegant (with ornate serifs), dating anytime 
Fig. 2 PLond 1.24 (c. 162 BC), line 8 , hooked alpha followed by tau, representing 1300. Detail from British Museum 1893, plate 18

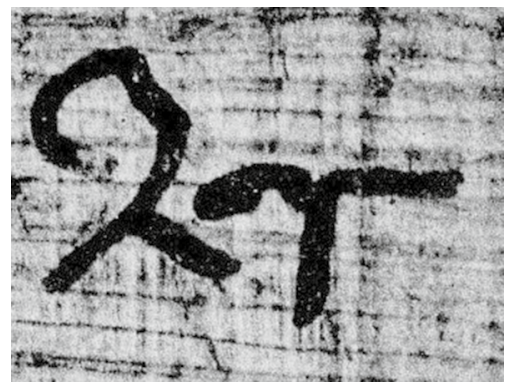

Fig. 3 PTebt 1.121 (either 94 or 61 BC), line 61, hooked alpha followed by chi, representing 1600. Image: Center for the Tebtunis Papyri, University of California, Berkeley
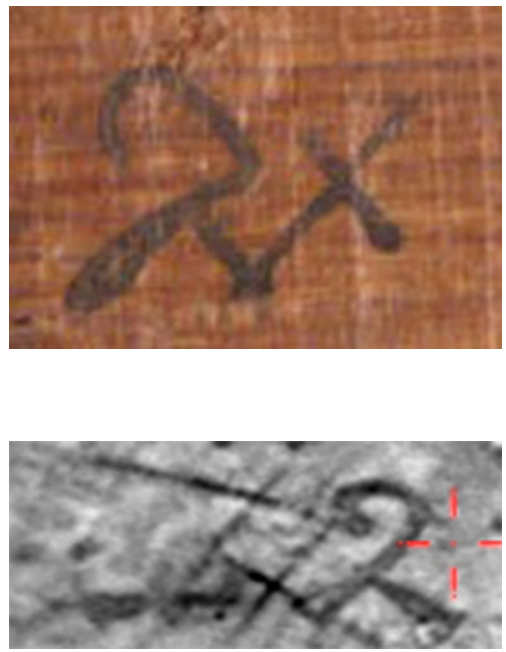

Fig. 4 BPI line 31, cursive omega and hooked alpha. CT image derived from Freeth 2018, Creative Commons Attribution (CC BY) license

between the end of the third-century and the middle of first-century BCE. The identification of the cursive omega, $\omega$, in lines 5 and 31 requires comment, along with the symbol in line 31 that we transcribe as $\hat{A}$. On inscriptions, the shape $\omega$ for $\Omega$ begins to appear regularly in the second half of the first-century $\mathrm{BCE},{ }^{21}$ which might argue for a date closer to the time of the shipwreck, but it was already the standard form in the papyrological tradition by the end of the third-century BCE. Gregg Schwendner previously suggested that 2 was a hooked cursive alpha that stands for the numeral 1,000 on papyri, and in fact it would be easy to compile many examples of Greek papyri from throughout the Hellenistic period in which 1,000 is written very similarly to the symbol in the BPI (e.g., Figs. 2, 3, and for comparison, Fig. 4). ${ }^{22}$

\footnotetext{
21 A few rare earlier examples can be found. For instance, Lougovaya 2015, 113 reports that SEG LIX 1767B (=Lougovaya 2015, 108, B), which comes from Ptolemaic Narmouthis (Egypt) and dates sometime from 117 to $115 \mathrm{BCE}$, has a cursive omega in line 3, as well as cursive forms for pi and mu more typically found on papyri, mixed in with non-cursive forms. SEG LIV 1568, which is from Alexandria Arachosia and dates to the late second-century BCE, also reports a cursive omega.

22 On inscriptions, the use of a hook over a letter to indicate thousands is very rare (instead, typically a tick to the bottom left of a letter is used). One of the few examples of a type of hook is found on the "Keskintos Astronomical Inscription" from Rhodes (=IG XII,1 913), which is dated ca. 150-50 BCE.
} 
The presence of a cursive omega as the last index letter of the group that was inscribed in line 5, together with the presence of a barred cursive omega and a hooked alpha as the first two index letters of the group in line 31, has important implications for reconstructing the theory underlying the Mechanism's eclipse prediction scheme, as we will see in the subsequent analysis. We may anticipate some outcomes that have paleographical significance. Firstly, the cursive omega in 5 is functionally the 24th letter of the first alphabetic sequence, linking to the 24th eclipse glyph on the Saros Dial; it is not treated as a special symbol distinct from a "normal" omega. In other words, this is simply how the engraver chose to make omegas when they came up as index letters in the BPI, and by implication, probably also on the Saros Dial Scale. Secondly, it can be shown that the first two index letters in 31 must belong to cells 213 and 219, right at the end of the Saros cycle. The barred omega is the last letter of the second alphabetic sequence; hence, it is the index letter of cell 213 and of the 48th glyph. Our other evidence for the eclipse sequence allows for an alternative reconstruction for the final cells: Either of the cells 213 and 219 was the final two containing glyphs, or cell 214 also had a glyph. With the former option, it would make sense to assign to cell 219 an index letter alpha, modified so as to appear as belonging to a third alphabetic sequence (even if this sequence turns out to go no further!). This amounts to further confirmation that the 2 is to be understood as hooked alpha, while simultaneously eliminating cell 214 as a candidate for a glyph. We thus have two letter forms appearing in the Mechanism's eclipse inscriptions (and only there) that, within the time span possible for the Mechanism's manufacture, were well established in the papyrological tradition but not in inscriptions. ${ }^{23}$ Just why the more normal epigraphical forms were not used is difficult to say, but we would conjecture that it had something to do with the Vorlage that he was following for this part of the Mechanism's inscriptions.

Other letter forms typically used to date inscriptions and occurring in the Mechanism's inscriptions include $\Pi$ as $\Gamma$ (with shorter right leg), $\Sigma$ as $\Sigma$ (with the two splaying horizontal hastae), $M$ as $M$ (with the two side strokes not vertical, but splayed), $\mathrm{Y}$ as $\mathrm{Y}$ (with a short vertical line), $\mathrm{Z}$ as $I$ (vertical rather than oblique hasta), B as B (with uneven circles, the upper smaller than the lower), $\mathrm{O}$ as $O$ (very small and raised), $\Theta$ as ${ }_{\theta}$ (theta with short line in the middle rather than a dot, found only in the Back Cover Inscription), $\Phi$ as $\Phi$ (with arc-like shape), and $\Xi$ as 王 (with a fourth, vertical hasta, apparently found only in numerals in the Front Cover Inscription). While these letter forms are more common at the end of the third and throughout the second-century BCE, they are attested on inscriptions all the way to the middle of the first-century BCE. ${ }^{24}$ Furthermore, a large part of the reason why they are

Footnote 22 (continued)

Here a downward-facing semicircular arc is placed above and to the left of the letter to indicate thousands, but the letters have the same epigraphic forms as elsewhere in the inscription. See Jones 2006a (=SEG LVI 953), Jones (2006b) and Bevan et al. (forthcoming).

23 Since these forms appear in papyri throughout the interval from the late third- to the mid-first-century $\mathrm{BCE}$, they do not help narrow down the range of dates within which the Mechanism could have been constructed.

24 Iversen will have more to say about specific letter shapes in a forthcoming article in a Festschrift in honor of James Evans. 


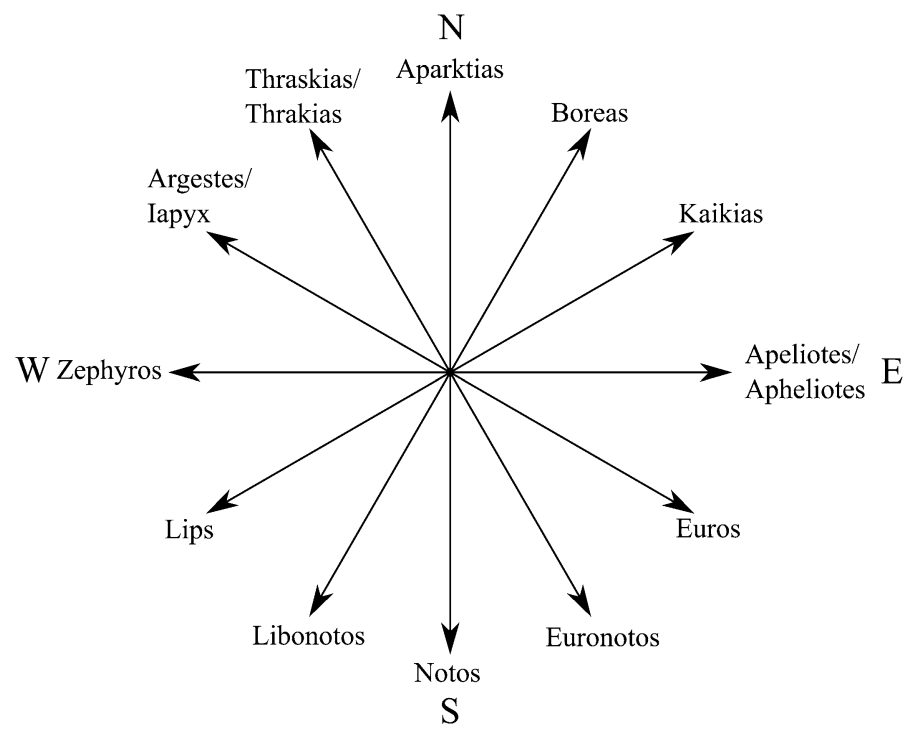

Fig. 5 12-fold windrose according to the third-century BC geographer Timosthenes. Alternate versions of wind names are as inscribed on the second-third-century bilingual marble anemoscope found near the Esquiline, now in the Museo Pio-Clementino, Musei Vaticani (IGUR IV.1648)

more common ca. 200-150 BCE is undoubtedly due to the fact that lettering on inscriptions in that period was typically much smaller $(4-6 \mathrm{~mm})$, and in order to make the smaller letters more legible, they needed more volume, which is accomplished by making letters that are more squat with flaring strokes. The flaring of the strokes also prevents the hastae from sloppily running over each other, especially at angular corners such as on sigmas and mus. To sum up, the extremely small size of these letters is a big factor in their shape, and in any case all these letters could have been employed anytime from the end of the third to the middle of the first-century BCE. We have discussed elsewhere why we think the Mechanism dates closer in time to the shipwreck, or ca. $100-50$ BCE. $^{25}$

\subsection{The restoration of BPI 1-5 as a paragraph of eclipse descriptions}

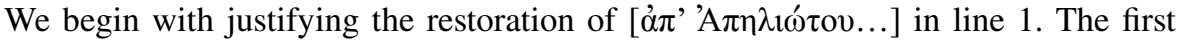
thing to note is that each of the successive starting " $\alpha$ ' ó" points of the preserved Index Letter Groups at the beginnings of lines 6,11, 21 and 32 is moving in a counterclockwise direction on a windrose as one reads through the inscription. In addition, each of the directional " $\pi \rho \varsigma \varsigma$ " statements also probably "wheels about" counterclockwise in respect to its beginning " $\alpha$ สó" point. This can be seen by consulting the dodecagonal windrose diagram in Fig. 5.

25 Jones (2017: 93 and 157), Iversen (2017: 182-183). 


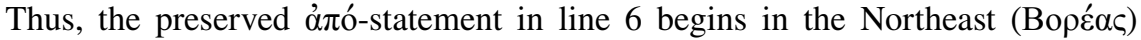
and its $\pi \rho$ ó $\varsigma$-statement wheels around counterclockwise to the Southeast ( $\Lambda$ í $\psi$ ); the

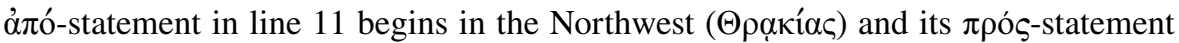
wheels about counterclockwise to the East (A $\pi \eta \lambda \imath \omega \dot{\tau} \eta \varsigma) .{ }^{26}$ Likewise, line 21 begins in the West (Z'́́, East ('A $\pi \eta \lambda \iota \dot{\tau} \tau \varsigma)$, and line 31 begins in the South (Nó $\tau$ os) and wheels about counterclockwise to the East ('A $\pi \eta \lambda \iota \omega ́ \tau \eta \varsigma)$. This means that the missing opening á $\boldsymbol{\alpha o ́}^{-}$ statement above the first partially preserved line is very likely to have begun in the

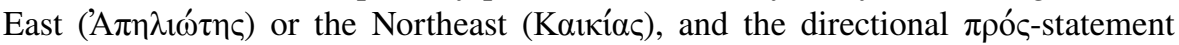
is counterclockwise from this starting point. Between these two, it makes the most sense to begin at a cardinal point; hence, 'A $\pi \eta \lambda \iota \omega ́ \tau \eta \varsigma$ is likely to be the starting point of the lost $\dot{\alpha} \pi$ ó-statement in line 1 . This also has the effect of making the starting points on the north half of the windrose symmetrical with each other.

After these directional considerations, in lines 1-4 spacing and color constraints then come into play. As Fig. 1 makes clear, if lines 2-4 were indented, there are about 10 letters missing at the beginning of line 3 and nine letters missing at the beginning of line 4 . Furthermore, given the small magnitude of the eclipses referenced, we would expect a dark color. Consequently, the restoration of $[\chi \rho \hat{\omega} \mu \alpha \kappa \varepsilon \lambda]$ Q̊vóv in line 4 is highly likely. Since all the other opening directional/wind statements in the upper half of the Back Plate Inscription begin with the word àjò dedented one or two letters to the left in respect to the left margin of the line that follows, it stands to reason that this is the case in line 1 . The best fit, therefore, is

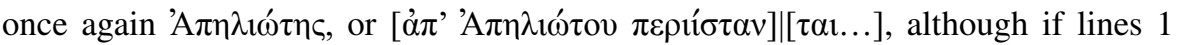

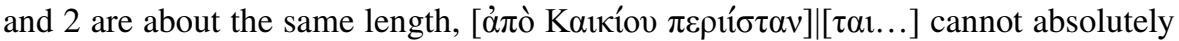
be ruled out. As noted above, however, it seems more likely that at least one of the $\dot{\alpha} \pi$ ó-statements would begin with the cardinal point in the East.

As for line 3, spacing and directional considerations mean that the restorations

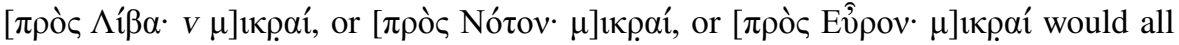
fit.

There is, however, the possibility that, as at lines 21-27, two $\pi \rho$ ó $\varsigma$-statements follow the áró-statement. Thus, we could posit there is a missing line above the first preserved line. In this case, due to the likely spacing constraints, we would need longer names for the $\dot{\alpha} \pi$ ó-statement and the first $\pi \rho \mathrm{o}_{\varsigma}$-statement, as in the following example:

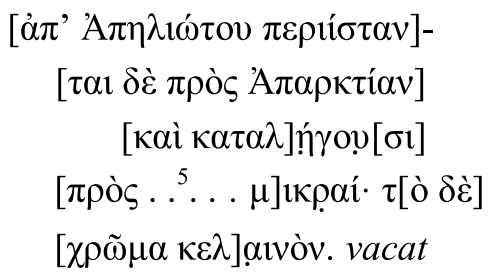

\footnotetext{
${ }^{26}$ The wind $\Theta \rho \alpha \kappa^{\prime} \alpha \varsigma$ is also commonly spelled $\Theta \rho \alpha \sigma \kappa i \alpha \varsigma$, with or without and iota subscript or adscript

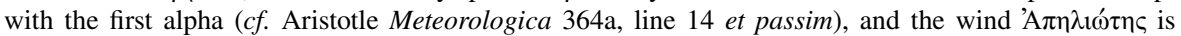

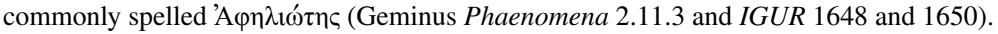


The spacing of line three of this arrangement (with only 14 letters), however, seems very unlikely, and since there isn't room to fit $\pi \rho$ ò $\varsigma$ at the end of this line (the inscriber observes word or syllabic division at the ends of lines), there are no good candidates to make the spacing fit.

\subsection{Discussion of Freeth's reconstruction of the layout of the BPI}

This leads us to a discussion of the likely layout of all the inscriptions on the Back Plate describing the lunar and solar eclipses. As noted above, Freeth (2014) has argued that the solar eclipses were described on each side of the Saros Dial and that the lunar eclipses, which probably numbered 38, on each side of the Metonic Spiral. Alternatively, Anastasiou et al. 2016 have suggested that all the solar eclipses were located only on the preserved right side of the Saros Dial, while the 38 lunar eclipses were described on the lost left side of the Saros Dial. Freeth (2019), on the other hand, recently reiterated his support for his 2014 version, by arguing that:

1. Lines 1-4 were not part of an Index Letter Group as is the case on the rest of this inscription, but possibly some sort of introductory text.

2. Line 5 of the inscription did not have index letters, and the last letter of this line is not $\omega$ (cursive omega), as Anastasiou et al. 2016 suggest, but an O (omicron).

3. The index letter $\overline{\mathrm{A}}$ is not found at the beginning of line 10, as Anastasiou et al. 2016 have it.

4. The traces at the beginning of line 31 do not support Anastasiou et al.'s contention that these are the remains of three missing index letters before the symbol 2 .

5. There was a solar glyph in the non-extant cell 149, contrary to Anastasiou et al. 2016.

6. 51 cells of the Saros Dial have glyphs in them indicating a lunar or solar or lunar and solar eclipse, not 49, as Anastasiou et al. argue.

7. There is not enough room for the all the solar eclipses on the right side of the Saros Dial, nor the 38 lunar eclipses on the left side of the Saros Dial, as Anastasiou et al. 2016 have it.

Of these points, 4 and 5 are valid, but the others are not.

Point 1. The remains of line 2 are completely consistent with the verb $\kappa \alpha \tau \alpha \lambda \eta ́ \gamma \sigma v \sigma$, the remains of line 3 include the word $\mu$ í $\rho \alpha$, as Freeth himself acknowledges, and the spacing that follows favors the appearance of a color, and the traces are consistent with a black color. It has also been shown that the spacing of the new line 1 is consistent with the very likely wind to be mentioned. The collocation of all these facts inclines strongly to reading lines 1-4 as part of an Index Letter Group.

Point 2. Freeth contends that the letter at the end of line 5 is not a cursive omega, $\omega$. Part of his argument is that cursive omegas are not found elsewhere on the Mechanism, except in the glyph-monogram $\hat{\omega} \rho \alpha$. His other argument is that the traces at the end of line 5 are consistent with omicrons found elsewhere 
on the Mechanism. The first index letter in line 31, however, is, in fact, a clear, completely preserved cursive omega. Ironically, Freeth himself draws it as a fully preserved cursive omega in Figs. 2, 4, and 6 of his 2019 article. There is thus no doubt what letter strokes are preserved there, nor is it at all plausible that these letter strokes belong to any other letter besides a cursive omega.

Furthermore, the shape and size of this cursive omega perfectly match the remains at the end of line 5, which contrary to Freeth's claims are not consistent with the omicrons found elsewhere on the Mechanism. In particular, omicrons are much smaller (in keeping with their name, o-mikron, "little o"), they do not have a loop that flares so widely to the right, and, unlike the letter at the end of line 5, they are connected at the top or certainly do not have as large a gap in the loop. Consequently, epigraphical considerations indicate that the remains of the letter at the end of line 5 belong to a cursive omega, as Anastasiou et al. suspected, and no other letter shape thus far found on the Mechanism will do; hence, there is no need to dot this letter. Since the cursive omega appears to have been employed only as an index letter, this strongly, if not decisively, indicates that lines 1-5 are part of an Index Letter Group.

In addition to the positive epigraphical arguments for cursive omega and the clear parallel of the cursive omega in line 31 as an index letter, there are also numerous other contextual problems with not reading the last letter in line 5 as an index letter and instead interpreting it as an omicron. First, as noted in the apparatus criticus at line 4 , more evidence has come to light that strongly suggests the correct restoration is $[\delta \grave{\varepsilon} \chi \rho \hat{\omega} \mu \alpha \kappa \varepsilon \lambda] \alpha$ lvóv. This supplement occurs directly after Anastasiou's et al.'s correct reading in line 3 of the magnitude of the eclipses being $\mu$ í $\rho \propto 1$. In every other instance on this inscription, the magnitude is followed by the color, which is then followed by a line of index letters. Furthermore, on this inscription there are only two other places where two successive lines have large vacats at the end of them - that is at the ends of lines 9 and 10 and at the ends of 30 and 31. In each of these two other cases, the first line ends with the color followed by a vacat, and the second line has index letters followed by a vacat. Given the formulaic nature of this inscription, it is highly probable, therefore, that the letter at the end of line 5 is an index letter.

Moreover, if this omicron is not an index letter, as Freeth argues, then it must be the last letter of a word, since there is a large vacat after it and before a new ámóstatement begins line 6. There are, however, very few ancient Greek words in the Attic-Ionic dialect that end in omicron. These include the past tense forms of verbs

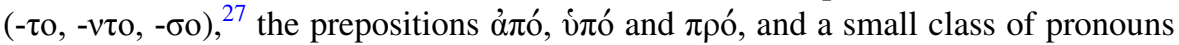

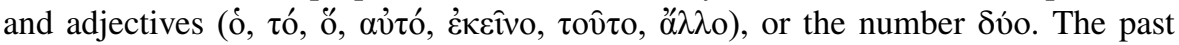
tense verb endings, the prepositions, the proclitics $\delta$, $\tau$ ó, and the relative pronoun of can all safely be excluded, as past tense verbs are not used on the Mechanism, and the proclitics ó, $\tau$ ó and relative pronoun ő and the prepositions $\alpha \pi$ ó, vं $\pi$ ó and $\pi \rho o ́$ all

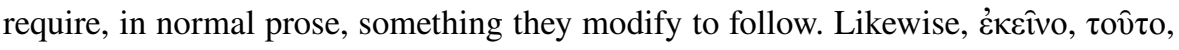

${ }^{27}$ The latter could also be the present, second person singular, imperative, middle form, but this is highly unlikely. 


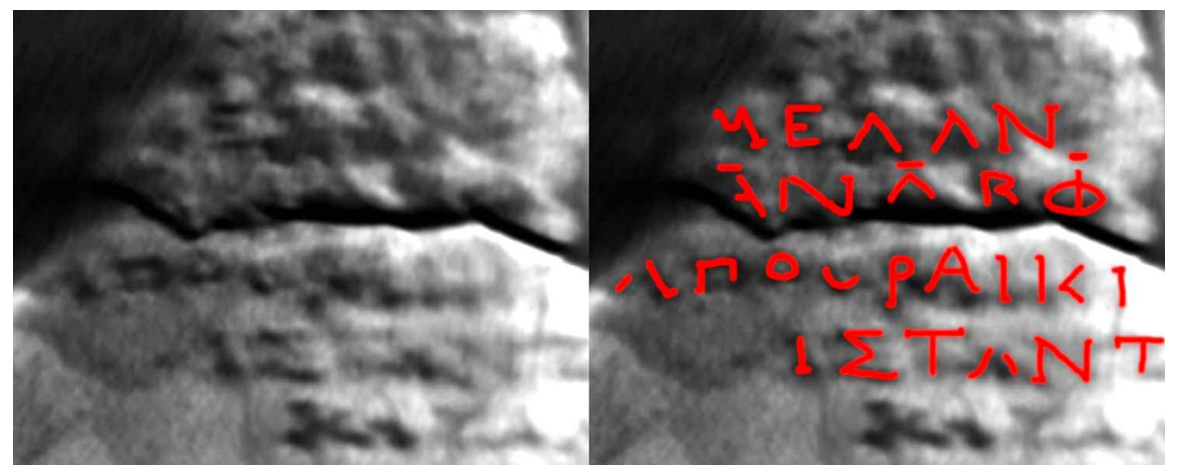

Fig. 6 BPI lines 7-12, with tracings of letters in lines 8-11. CT image derived from Gibson 2018, Creative Commons Attribution (CC BY) license

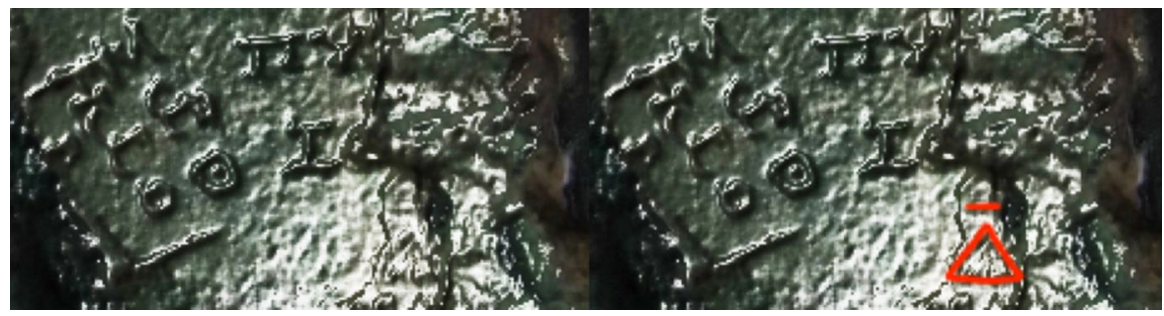

Fig. 7 BPI lines 18-20 (and eclipse glyph in Saros Dial cell 178), with traced delta in line 20. PTM image with specular enhancement from PTM ak49a, courtesy Antikythera Mechanism Research Project

and $\alpha^{\prime} \lambda \lambda_{0}$ are usually placed between the definite article $\tau$ ó and some other noun they modify; hence, they are rarely placed at the end of a sentence or clause. If one of these is to be supposed here, it must refer to a neuter singular noun that precedes, and the only reasonable possibility is $\chi \rho \hat{\omega} \mu \alpha$, but what would be the point of referring to "that color" or "this color" or "another color." That leaves only the number

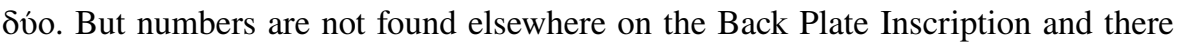
is no good explanation for one appearing here. All these considerations, both epigraphical and contextual, taken together mean that it is overwhelmingly likely that this letter is not an omicron, that it is a cursive omega, and that it is an index letter.

Point 3. Freeth insists that the index letter $\bar{A}$ is not found at the beginning of line 9, relying on what he is able to see in a PTM file. In Fig. 6, we give an image of the region around this line from the recently improved CT volume A6, together with a traced copy. ${ }^{28}$ The index letters $\bar{A} N \bar{\Lambda} \mathrm{B} \bar{\Phi}$ are visible running along the fracture, which runs diagonally across the alpha and thereafter horizontally across the other index letters slightly above baseline height. See the apparatus criticus above for more on these readings.

${ }^{28}$ Data at Gibson (2018); see also Pakzad et al. (2018). 
Point 4. Freeth is correct that the traces at the beginning of line 31 are not consistent with restoring three letters $(\Lambda \Xi$, tentatively read by Anastasiou et al. as $\Delta \Lambda \Xi$ ) before the hooked alpha 2. We have seen this line is to be read vac. $\bar{\omega} \hat{A} \bar{\Pi} K \bar{Z} \Phi$ vac. However, the first of the three letters read by Anastasiou et al. at the beginning of line 31 , namely $\bar{\Delta}$, is now to be found in the new line 20, and the other two can be restored there, or $\bar{\Delta}[\Lambda \bar{\Xi}]$, as shown in Fig. 7 .

Point 5. It will be shown in the Analysis section that the eclipse scheme of Anastasiou et al. should be modified to include a solar eclipse in cell 149. However, it will also be shown that his eclipse scheme requires modification with respect to two other non-extant cells. A new scheme for the distribution of the glyphs will be proffered that accounts for the new information concerning the index letter groups and appears to be the only possible one consistent with all the evidence, involving only 49 cells with glyphs on the Saros Dial, not 50 or 51 as in previous reconstructions. ${ }^{29}$

Point 6. Anastasiou et al. argued that all the relevant solar eclipses are covered by the paragraphs in the existing BPI which occupies the middle and lower of the three roughly triangular spaces along the right side of the Back Plate outside the Metonic and Saros Dials and hence that the lunar eclipse paragraphs were found in all three spaces along the lost left side of the Back Plate and in the lost space in the upper right corner outside the Metonic Dial. Freeth speaks of this as "an unattractive breaking of the symmetry of the layout," but in considering the question of the layout, hypothetical aesthetic preferences held by the ancient designer are at best secondary to the evidence offered by the extant parts of the inscription. Freeth 2014 situated two paragraphs of solar eclipse descriptions along the left side of the Saros Dial because two sequences of index letters predicted by his model for generating and ordering the solar eclipse possibilities according to progressively decreasing mean lunar latitude seemed to be missing from the paragraphs along the right side: $\Gamma \Xi \Omega \overline{\mathrm{A}}$ at the beginning, and $\bar{\Delta} \Lambda \bar{\Xi}$ (special symbol) between the index letter groups in lines 19 and 31. Of the supposedly missing first sequence, we have shown that the omega is extant in line 5, following fragmentarily preserved lines of text that can be credibly restored as eclipse descriptions similar to the better preserved ones, and the barred alpha is extant at the beginning of line 10, while the other two letters can easily be accommodated in the lost part of line 5 preceding the omega. We have also shown that the first of the letters of the second supposedly missing sequence, barred delta, is extant in the previously unnoticed line 20 , with enough room in the lost part of line 20 to the right of this letter to accommodate the two or three index letters (depending on which eclipse possibility scheme one adopts) between barred delta and the first index letters of line 31. Thus, while it cannot be proved that the two left-side paragraphs reconstructed by Freeth did not exist, with so few index letters unaccounted for and plenty of room for them in the lost parts of lines 5 and

\footnotetext{
29 Freeth (2014, 2019) has 51 (including the non-extant cells 207, 208, 213, 214, and 219), whereas Anastasiou et al. 2016 allow either 51 (with glyphs in the same give final cells as Freeth) or 50 (with no glyph in 214), in either case further hypothesizing that cells 213 and 219 used the same index symbol. The reconstruction presented later in the present paper has no glyphs in cells 207 or 214.
} 
20 the hypothesis of left-side solar paragraphs becomes not just unnecessary, but gratuitous.

Why would four of the six spaces around the dials have been needed for the lunar eclipse descriptions while just two are enough for the solar descriptions? This could be accounted for in many ways. The number of lunar eclipse possibilities, 38, was significantly greater than the number of solar possibilities, 28 according to our reconstruction below. But the space requirements would have been driven not so much by the number of eclipse possibilities as by the number of groups into which they were partitioned, and the lengths of the descriptive texts. Without any surviving lunar paragraphs, we can only guess at these quantities; in fact, it is not to be taken for granted that the lunar possibilities were ordered and assigned to groups according to the same single criterion, mean lunar latitude, as the solar ones. For that matter, we cannot be sure that either of the spaces in the top corners of the Back Plate was used for the BPI; perhaps, it was just the four spaces adjacent to the Saros Dial.

Prefatory to our new analysis and reconstruction of the Mechanism's scheme for eclipse possibilities, we offer a summary of critical readings in the BPI lines and Saros Dial ${ }^{30}$ :

- lines 1-4, readings are consistent with restoration as a paragraph of eclipse descriptions, ${ }^{31}$ with the likely directional wind to be restored in line 1 as $[\alpha \dot{\alpha}$ '

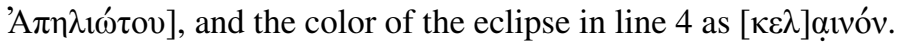

- line 5, the likely index letters to be restored at the beginning of the line and the confirmation that the last preserved traces in this line belong to a cursive omega, $\omega$, and not to a word ending in $-\mathrm{O} .{ }^{32}$

- line 10 , reading barred alpha as the first letter of the index letter row, preceding the undisputed nu. ${ }^{33}$

- line 19, confirming the xi (that does not need to be dotted) at the end of the line. ${ }^{34}$

- line 20, asserting the existence of this line for the first time as a continuation of the index letter row of line 19, with traces of a barred delta as the first letter.

- line 31, the index letter row is now read as $\bar{\omega} \hat{A} \bar{\Pi} K \bar{Z} \Phi$ with the first letter in the line a barred cursive omega (with no letters preceding the omega) and the second letter confirmed as a hooked alpha. ${ }^{35}$

- line 38 , there is no psi at the end of this index letter row. ${ }^{36}$

\footnotetext{
30 Lines 2-19 and lines 21-38 have a line number higher by one than in Anastasiou et al. 2016.

31 Confirming Anastasiou et al. (2016, 163).

32 Confirming Anastasiou et al. (2016, 163 and 165) against Freeth (2019, 11).

33 Confirming Anastasiou et al. (2016, 163 and 166) against Freeth $(2019,7)$ (which is not quite categorical).

34 Confirming Freeth (2014), Fig. S6 (doubtful) and Anastasiou et al. (2016, 164) (doubtful).

35 Against Freeth (2014), Fig. S6 (Â transcribed as 2, with no preceding letters), Anastasiou et al. 2016, 164 and 167-8 (reading an unidentifiable letter, lambda, and xi preceding Â), and Freeth $(2019,8)$.

36 Against Freeth $(2014,9)$ and Fig. S6 (not categorical) and Anastasiou et al. $(2016,164)$ and 168 (also doubtful).
} 
- cell 8 , reading a daytime lunar eclipse at the 2 nd hour and a daytime solar eclipse at the first or fourth hour for the first time.

- cell 61, reading a trace of the sigma of $\Sigma(\eta \lambda \eta ́ v \eta)$ in line 1 for the first time.

- cell 67 , confirming the nighttime lunar eclipse at the eighth hour. ${ }^{37}$

- cell 72, confirming a solar eclipse at the second hour. ${ }^{38}$

- cell 119, confirming the nighttime solar eclipse at the twelfth hour. ${ }^{39}$

- cell 120 , confirming the daytime lunar eclipse as possibly at the 12 th hour. ${ }^{40}$

- cell 125 , confirming a daytime lunar eclipse at the 8 th hour in line $1 .^{41}$

\section{Analysis}

\subsection{Reconstruction of the EP scheme}

As already outlined in section 1, the following principles are well established and not in dispute:

1. At spacing of six or five cells, with an average spacing of 223/38 (i.e., approximately 5.87 ) cells, along the Saros Dial Scale and separated by vacant cells, one of the following three patterns of glyphs was inscribed:

a. A cell containing a solar glyph followed by a cell containing a lunar glyph, signifying a solar EP at the end of the former month followed by a lunar EP in the middle of the latter month.

b. A single cell containing both a lunar glyph and a solar glyph, signifying a lunar EP at the middle of the month followed by a solar EP at the end of the month.

c. A single cell containing only a lunar glyph, signifying a lunar EP in the middle of the month, with no solar EP in either the same or the preceding month.

2. The lunar EPs form five groups of 7 or 8 spaced at intervals of six cells, with each group separated from its neighbors at intervals of five cells, in an 8-7-8-7-8 cyclic pattern beginning with either cell 37 or cell 172 . The only difference between the two possibilities is that in the pattern beginning with cell 37, a lunar EP would fall in cell 213, but in the pattern beginning with cell 172, the EP in question falls in cell 214. The 8-7-8-7-8 pattern can be modeled as a consequence of an assumption that an opposition is a lunar EP if and only if the mean lunar latitude at opposition (i.e., neglecting the effect of lunar anomaly) falls between a pair of positive and negative limiting values that are symmetrically situated with respect

\footnotetext{
37 As at Anastasiou et al. (2016, 159 and 161).

38 As at Freeth/Crowther 2014, 5 (Fig. 4) and Anastasiou et al. (2016, 159 and 161) (but doubtful).

39 As at Anastasiou et al. (2016, 159 and 161), against Freeth (2019, 2) (Fig. 1).

40 As at Freeth/Crowther 2014, S13, 125, against Anastasiou et al. (2016, 159 and 162) (dotted epsilon).

41 As at Anastasiou et al. $(2016,159)$ against Freeth (2019).
} 
Table 1 EPs attested or deducible from principle 1

\begin{tabular}{|c|c|c|c|}
\hline Cell & Lunar EP & Solar EP & Index \\
\hline 2 & [Yes] & & {$[\mathrm{A}]$} \\
\hline 8 & Yes & Yes & B \\
\hline 13 & No & Yes & $\Gamma$ \\
\hline 14 & [Yes] & {$[\mathrm{No}]$} & {$[\Delta]$} \\
\hline 20 & Yes & No & E \\
\hline 25 & No & Yes & Z \\
\hline 26 & Yes & No & $\mathrm{H}$ \\
\hline 31 & {$[\mathrm{No}]$} & [Yes] & {$[\Theta]$} \\
\hline 32 & [Yes] & {$[\mathrm{No}]$} & {$[\mathrm{I}]$} \\
\hline 37 & [Yes] & & {$[\mathrm{K}]$} \\
\hline 43 & [Yes] & & \\
\hline 49 & [Yes] & & \\
\hline 55 & [Yes] & & \\
\hline 61 & Yes & & {$[\mathrm{O}]$} \\
\hline 67 & Yes & No & $\Pi$ \\
\hline 72 & No & Yes & $\mathrm{P}$ \\
\hline 73 & [Yes] & {$[\mathrm{No}]$} & {$[\Sigma]$} \\
\hline 78 & No & Yes & $\mathrm{T}$ \\
\hline 79 & Yes & No & $\Upsilon$ \\
\hline 84 & [Yes] & & {$[\Phi]$} \\
\hline
\end{tabular}

$[\overline{\mathrm{B}}]$

No

No

Yes

No

Yes

Yes

Yes

$\bar{\Gamma}$

$\bar{\Delta}$

$\overline{\mathrm{E}}$

$\bar{Z}$

$\overline{\mathrm{H}}$

$\bar{\Theta}$

[Yes]

[Yes]

[Yes]

[Yes]

[Yes]

[ত] ]

$\bar{\Pi}$

$\overline{\mathrm{P}}$

Yes

Yes

Yes

Yes

No

$\bar{\Sigma}$

$\overline{\mathrm{T}}$

\begin{tabular}{llll}
190 & Yes & No & $\bar{T}$ \\
196 & {$[$ Yes $]$} & & \\
202 & {$[$ Yes $]$} & & \\
208 & {$[$ Yes $]$} & & \\
\hline
\end{tabular}


Table 1 (continued)

\begin{tabular}{llll}
\hline Cell & Lunar EP & Solar EP & Index \\
\hline 213 or 214 & {$[$ Yes $]$} & & \\
219 & {$[$ Yes $]$} & & \\
\hline
\end{tabular}

to the ecliptic (latitude $0^{\circ}$ ) and just far enough apart so that one and only one lunar EP occurs every six or five months.

3. The solar EPs can be modeled by the assumption that conjunction is a solar EP if and only if the mean lunar latitude (again neglecting lunar anomaly) falls between a pair of positive and negative limiting values that are asymmetrically situated with respect to latitude $0^{\circ}$, with the positive limit greater than the absolute value of the negative limit, and with the limits sufficiently close together so that at most one solar EP occurs every six or five months. ${ }^{42}$ Compared to the latitudinal limits for the lunar EPs, the lower limit for the solar EPs must have been significantly closer to zero, whereas the upper limits must have been fairly close to each other in value.

4. For the purposes of assigning solar EPs to groups having the same predicted attendant qualitative phenomena in the BPI, the sequence of solar EPs was sorted in order of decreasing mean lunar latitude and then partitioned into groups; the corresponding index letters were listed in order of decreasing mean lunar latitude at the end of each paragraph of the BPI. The partitioning can be modeled by the assumption that all solar EPs sharing the same qualitative phenomena have mean lunar latitude between certain limiting values.

Principle 2 would fully determine the entire pattern of lunar EPs and principles 3 and 4 the entire pattern of solar EPs, including their groupings according to paragraphs in the BPI, if (a) the method and parameters for calculating the mean lunar latitudes were known, and (b) the boundary values were known. Moreover, since the lunar EP sequence is already established with the sole exception of uncertainty whether a lunar EP fell in cell 213 or 214, a fully determined solar EP pattern would give us a complete determination of the correlation of index letters with all cells except for a few at the end of the Saros_and even this last uncertainty might be resolved through the evidence of the index letter groups in the BPI.

To begin with, then, Table 1 gives the cells of all the lunar EPs as generated by principle 2, merged with the lunar and solar EPs and their index letters as attested on or deducible from the surviving fragments of the Saros Dial Scale. Deduced data are enclosed in brackets.

\footnotetext{
${ }^{42}$ In Anastasiou et al. (2016, 181-182), it was additionally assumed that the solar EPs were a subset of an 8-7-8-7-8 pattern aligned for astronomical consistency with the lunar EP pattern. We agree with Freeth $(2019,7)$ that this additional condition is gratuitous. Applying the condition would remove solar EPs otherwise predicted for cells 149 and (possibly) 196, in parts of the Saros not preserved in the extant fragments, though the correlation of index letters with cells would not be affected since the solar EPs in question fall months that have lunar EPs.
} 
Table 2 Computed lunar latitudes for conjunctions that are candidates for solar EPs

\begin{tabular}{|c|c|c|}
\hline Cell & Mean latitude & Index \\
\hline 2 & -0.552 & \\
\hline 8 & 0.900 & B \\
\hline 13 & 1.402 & $\Gamma$ \\
\hline 19 & -1.062 & No EP \\
\hline 25 & 0.716 & Z \\
\hline 31 & -0.367 & $\Theta$ \\
\hline 37 & 0.017 & \\
\hline 43 & 0.334 & \\
\hline 49 & -0.683 & \\
\hline 55 & 1.029 & \\
\hline 60 & 1.274 & \\
\hline 66 & -0.932 & \\
\hline 72 & 0.585 & $\mathrm{P}$ \\
\hline 78 & -0.235 & $\mathrm{~T}$ \\
\hline 84 & -0.116 & \\
\hline 90 & 0.466 & \\
\hline 96 & -0.814 & \\
\hline 102 & 1.158 & \\
\hline 107 & 1.146 & \\
\hline 113 & -0.802 & No EP \\
\hline 119 & 0.454 & $\bar{\Delta}$ \\
\hline 125 & -0.103 & $\overline{\mathrm{Z}}$ \\
\hline 131 & -0.248 & $\overline{\mathrm{H}}$ \\
\hline 137 & 0.598 & $\bar{\Theta}$ \\
\hline 143 & -0.944 & \\
\hline 148 & -1.358 & \\
\hline 149 & 1.287 & \\
\hline 154 & 1.017 & \\
\hline 160 & -0.671 & \\
\hline 166 & 0.322 & \\
\hline 172 & 0.029 & $\bar{\Pi}$ \\
\hline 178 & -0.380 & $\overline{\mathrm{P}}$ \\
\hline 184 & 0.729 & $\bar{\Sigma}$ \\
\hline 190 & -1.074 & No EP \\
\hline 195 & -1.230 & \\
\hline 196 & 1.414 & \\
\hline 201 & 0.887 & \\
\hline 207 & -0.540 & \\
\hline 213 & 0.190 & \\
\hline 219 & 0.161 & \\
\hline
\end{tabular}




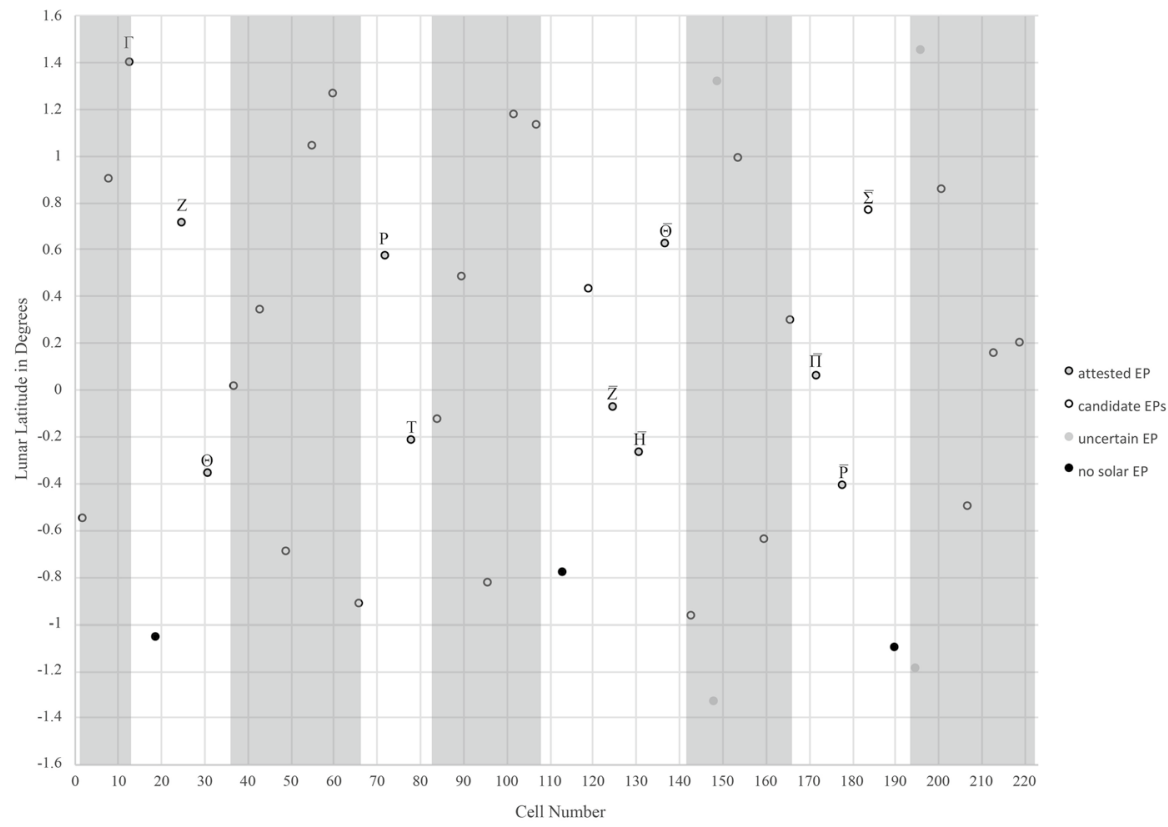

Fig. 8 Mean latitudes of the conjunctions from Table 2

At this stage, there are four gaps in the index letter sequence. Between cells 37 and 66, five letters are unaccounted for, of which four would have been assigned to the cells with the known lunar EPs (whether or not they also contained solar EPs), so there must also have been one solar EP in this interval in a month preceding a lunar EP. Between cells 84 and 108, there are known to be three lunar EPs and four letters unaccounted for (plus conceivably one or more additional symbols appended to the first alphabetic sequence), so that at least one solar EP must have been in a month preceding a lunar EP. Between cells 143 and 167, there are known to be four lunar EPs and six letters unaccounted for, so that two solar EPs must have been in months preceding lunar EPs. Lastly, after cell 190 there are exactly enough known lunar EPs to account for the five remaining letters of the second alphabetic sequence, but the number of additional solar EPs in months preceding lunar EPs is not determined because we know from BPI line 29 that there was at least one index letter or symbol in addition to the two complete alphabets.

Although we do not know precisely how mean lunar latitudes would have been calculated to prepare the data for the Mechanism's eclipse predictions, it will be sufficient for our purposes to have a model that yields approximately correct latitudes corresponding to the elongation of the mean syzygy from the lunar node. The phase alignment of the latitude function as well as the limiting values for the solar EPs and their subgroups can be determined empirically, within fairly tight bounds, by comparison of the solar EP model's predictions with the attested solar EPs on the Saros Dial Scale and with the more secure readings of index letter groups in the BPI. Assuming a period relation as follows: 
Table 3 EPs attested or deducible from principles 1 and 3

\begin{tabular}{|c|c|c|c|}
\hline Cell & Lunar EP & Solar EP & Index \\
\hline 2 & [Yes] & [?] & {$[\mathrm{A}]$} \\
\hline 8 & Yes & Yes & B \\
\hline 13 & No & Yes & $\Gamma$ \\
\hline 14 & [Yes] & {$[\mathrm{No}]$} & {$[\Delta]$} \\
\hline 20 & Yes & No & $\mathrm{E}$ \\
\hline 25 & No & Yes & $\mathrm{Z}$ \\
\hline 26 & Yes & No & $\mathrm{H}$ \\
\hline 31 & {$[\mathrm{No}]$} & [Yes] & {$[\Theta]$} \\
\hline 32 & [Yes] & {$[\mathrm{No}]$} & {$[\mathrm{I}]$} \\
\hline 37 & [Yes] & [Yes] & {$[\mathrm{K}]$} \\
\hline 43 & [Yes] & [Yes] & {$[\Lambda]$} \\
\hline 49 & [Yes] & {$[\mathrm{No}]$} & {$[\mathrm{M}]$} \\
\hline 55 & [Yes] & [Yes] & {$[\mathrm{N}]$} \\
\hline 60 & {$[\mathrm{No}]$} & [Yes] & {$[\Xi]$} \\
\hline 61 & Yes & {$[\mathrm{No}]$} & {$[\mathrm{O}]$} \\
\hline 67 & Yes & No & $\Pi$ \\
\hline 72 & No & Yes & $\mathrm{P}$ \\
\hline 73 & [Yes] & {$[\mathrm{No}]$} & {$[\Sigma]$} \\
\hline 78 & No & Yes & $\mathrm{T}$ \\
\hline 79 & Yes & No & $\Upsilon$ \\
\hline 84 & [Yes] & [Yes] & {$[\Phi]$} \\
\hline 90 & [Yes] & [Yes] & {$[\mathrm{X}]$} \\
\hline 96 & [Yes] & {$[\mathrm{No}]$} & {$[\Psi]$} \\
\hline 102 & [Yes] & [Yes] & {$[\omega]$} \\
\hline 107 & {$[\mathrm{No}]$} & [Yes] & {$[\overline{\mathrm{A}}]$} \\
\hline 108 & [Yes] & {$[\mathrm{No}]$} & {$[\overline{\mathrm{B}}]$} \\
\hline 114 & Yes & {$[\mathrm{No}]$} & $\bar{\Gamma}$ \\
\hline 119 & No & Yes & $\bar{\Delta}$ \\
\hline 120 & Yes & No & $\overline{\mathrm{E}}$ \\
\hline 125 & Yes & Yes & $\bar{Z}$ \\
\hline 131 & Yes & Yes & $\overline{\mathrm{H}}$ \\
\hline 137 & Yes & Yes & $\bar{\Theta}$ \\
\hline 143 & [Yes] & {$[\mathrm{No}]$} & {$[\overline{\mathrm{I}}]$} \\
\hline 149 & [Yes] & [Yes] & {$[\overline{\mathrm{K}}]$} \\
\hline 154 & {$[\mathrm{No}]$} & [Yes] & {$[\bar{\Lambda}]$} \\
\hline 155 & [Yes] & {$[\mathrm{No}]$} & {$[\overline{\mathrm{M}}]$} \\
\hline 161 & [Yes] & {$[\mathrm{No}]$} & {$[\overline{\mathrm{N}}]$} \\
\hline 166 & {$[\mathrm{No}]$} & [Yes] & {$[\bar{\Xi}]$} \\
\hline 167 & [Yes] & {$[\mathrm{No}]$} & {$[\overline{\mathrm{O}}]$} \\
\hline 172 & Yes & Yes & $\bar{\Pi}$ \\
\hline 178 & Yes & Yes & $\overline{\mathrm{P}}$ \\
\hline 184 & Yes & Yes & $\bar{\Sigma}$ \\
\hline 190 & Yes & No & $\overline{\mathrm{T}}$ \\
\hline
\end{tabular}


Table 3 (continued)

\begin{tabular}{llll}
\hline Cell & Lunar EP & Solar EP & Index \\
\hline 196 & {$[$ Yes $]$} & {$[$ Yes?] } & {$[\bar{Y}]$} \\
201 & {$[$ No $]$} & {$[$ Yes $]$} & {$[\bar{\Phi}]$} \\
202 & {$[$ Yes $]$} & {$[$ No $]$} & {$[\bar{X}]$} \\
207 & {$[$ No $]$} & {$[?]$} & \\
208 & {$[$ Yes $]$} & {$[$ No $]$} & \\
213 & {$[?]$} & {$[$ Yes $]$} & \\
214 & {$[?]$} & {$[$ No $]$} & \\
219 & {$[$ Yes $]$} & {$[$ Yes $]$} & \\
\hline
\end{tabular}

(1) $S$ synodic months $=D$ dracontic months

and denoting the mean latitude at the conjunction of cell $i$ as $\beta$, we have:

$$
\sin (\beta)=\sin \left(\beta_{\max }\right) \sin \left(360^{\circ} \times(D-S) / S \times i+k\right)
$$

where $\beta_{\max }$ is the maximum lunar latitude (approximately $5^{\circ}$ ) and $k$ is the elongation of the mean Moon from the ascending node at the mean conjunction preceding that of cell 1. Provisionally we will assume that the Saros is an exact relation for lunar latitude, i.e., $S=233$ and $D=242$, and use a phase shift calibrated empirically to maximize agreement of the data generated by the four principles with the attested data; hence,

$$
\sin (\beta)=\sin \left(5^{\circ}\right) \sin \left(360^{\circ} \times(19 / 223) \times i+125.0^{\circ}\right)
$$

Table 2 gives $\beta$ computed by formula (3) for the 40 conjunctions of the Saros that have the least $|\beta|$, that is, the 38 mean conjunctions that are closer to the node than those that immediately precede and follow, and two additional mean conjunctions whose elongations from the node are minimally greater than those of the neighboring mean conjunctions occurring on the other side of the same node.

We now turn to the problem of working out which conjunctions must be added to those of Table 1 as solar EPs to complete the index lettering scheme, bringing principle 3 into consideration. In Fig. 8, the mean latitudes from Table 2 are plotted, with markers distinguishing cells that are attested as having solar EPs in the extant inscriptions, with known index letters, and cells that are attested as not having solar EPs. The markers designated "uncertain" are the two additional mean conjunctions mentioned above and the conjunctions that immediately preceded them; one at most from each pair could have been a solar EP. Following principle 3, we do not expect any conjunction whose mean latitude was south of that of cell 113 to have been a solar EP, whereas any conjunction whose mean latitude was north of that of cell 178, except perhaps the "uncertain" cell 196 whose latitude is just north of that of the attested cell 13, should have been a solar EP. 
Table 4 Data from Table 2, with index letters from Table 3 , sorted in descending order of mean lunar latitude

\begin{tabular}{|c|c|c|}
\hline Cell & Mean latitude & Index \\
\hline 196 & 1.414 & 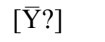 \\
\hline 13 & 1.402 & $\Gamma$ \\
\hline 149 & 1.287 & {$[\overline{\mathrm{K}}]$} \\
\hline 60 & 1.274 & {$[\Xi]$} \\
\hline 102 & 1.158 & {$[\omega]$} \\
\hline 107 & 1.146 & {$[\overline{\mathrm{A}}]$} \\
\hline 55 & 1.029 & {$[\mathrm{~N}]$} \\
\hline 154 & 1.017 & {$[\bar{\Lambda}]$} \\
\hline 8 & 0.900 & B \\
\hline 201 & 0.887 & {$[\bar{\Phi}]$} \\
\hline 184 & 0.729 & $\bar{\Sigma}$ \\
\hline 25 & 0.716 & Z \\
\hline 137 & 0.598 & $\bar{\Theta}$ \\
\hline 72 & 0.585 & $\mathrm{P}$ \\
\hline 90 & 0.466 & {$[\mathrm{X}]$} \\
\hline 119 & 0.454 & $\bar{\Delta}$ \\
\hline 43 & 0.334 & {$[\Lambda]$} \\
\hline 166 & 0.322 & {$[\bar{\Xi}]$} \\
\hline 219 & 0.190 & [?] \\
\hline 213 & 0.161 & [?] \\
\hline 172 & 0.029 & $\bar{\Pi}$ \\
\hline 37 & 0.017 & {$[\mathrm{~K}]$} \\
\hline 125 & -0.103 & $\bar{Z}$ \\
\hline 84 & -0.116 & {$[\Phi]$} \\
\hline 78 & -0.235 & $\mathrm{~T}$ \\
\hline 131 & -0.248 & $\overline{\mathrm{H}}$ \\
\hline 31 & -0.367 & $\Theta$ \\
\hline 178 & -0.380 & $\overline{\mathrm{P}}$ \\
\hline 207 & -0.540 & [?] \\
\hline 2 & -0.552 & [A?] \\
\hline 160 & -0.671 & [No EP] \\
\hline 49 & -0.683 & [No EP] \\
\hline 113 & -0.802 & No EP \\
\hline 96 & -0.814 & [No EP] \\
\hline 66 & -0.932 & [No EP] \\
\hline 143 & -0.944 & [No EP] \\
\hline 19 & -1.062 & No EP \\
\hline 190 & -1.074 & No EP \\
\hline 195 & -1.230 & [No EP] \\
\hline 148 & -1.358 & [No EP] \\
\hline
\end{tabular}




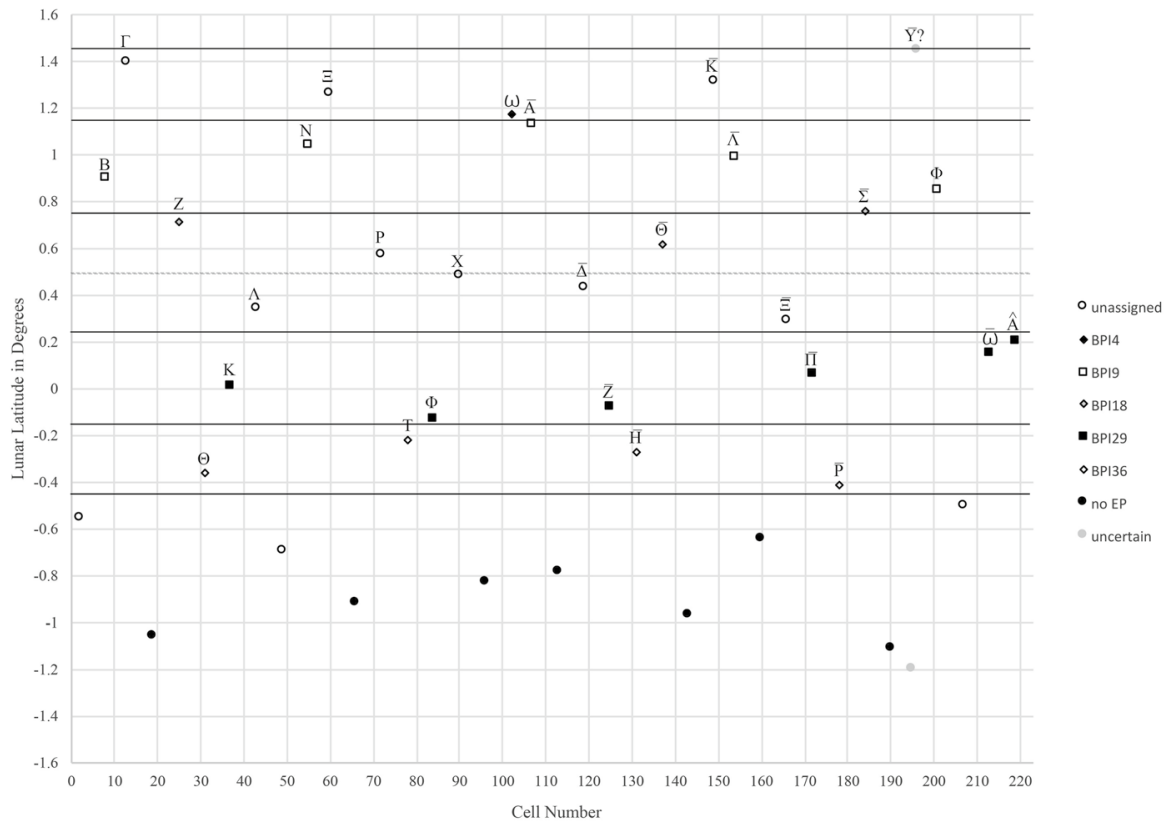

Fig. 9 Determination of the latitudinal zones for the BPI paragraphs

Zones shaded in gray are the gaps between secured index letters. Using the latitudes, we can now identify most of the solar EPs within the gaps:

- In the gap between cells 37 and 66, four candidate solar EPs (cells 37, 43, 49, and 55) would be in cells already known to have index letters from lunar EPs, so the remaining candidate (cell 60) must have had the fifth missing letter and thus was a solar EP.

- Between cells 84 and 108, together with the three already lettered candidates (cells 90, 96, and 102), cell 107 must have had a letter as a solar EP; we can also now rule out the possibility of additional index symbols between the first alphabetic sequence and the second since there are no other conjunctions in this gap that are candidates for solar EPs.

- Between cells 143 and 167, by the same reasoning as before, the two missing index letters must have belonged to solar EPs in two of cells 155, 161, and 167. Since the conjunction of cell 161 has a latitude south of the southernmost secured solar EP, it must be the excluded one, which also establishes that the lower latitudinal bound for solar EPs was north of this latitude.

- After cell 190, combining the information from Tables 1 and 2, cells 201, 213, and 219, but possibly not 207 or 214, had either solar or lunar EPs or both.

Hence, we can fill out Table 1 almost completely so far as index letters are concerned (Table 3), though uncertainty remains about cell 2, which had a lunar EP but may or may not have had a solar EP; about cell 207, which may or may not have had 
Table 5 Resolution of the EP sequence

\begin{tabular}{|c|c|c|c|}
\hline Cell & Lunar EP & Solar EP & Index \\
\hline 2 & [Yes] & {$[\mathrm{No}]$} & {$[\mathrm{A}]$} \\
\hline 8 & Yes & Yes & B \\
\hline 13 & No & Yes & $\Gamma$ \\
\hline 14 & [Yes] & {$[\mathrm{No}]$} & {$[\Delta]$} \\
\hline 20 & Yes & No & E \\
\hline 25 & No & Yes & Z \\
\hline 26 & Yes & No & $\mathrm{H}$ \\
\hline 31 & {$[\mathrm{No}]$} & [Yes] & {$[\Theta]$} \\
\hline 32 & [Yes] & {$[\mathrm{No}]$} & [I] \\
\hline 37 & [Yes] & [Yes] & {$[\mathrm{K}]$} \\
\hline 43 & [Yes] & [Yes] & {$[\Lambda]$} \\
\hline 49 & [Yes] & {$[\mathrm{No}]$} & {$[\mathrm{M}]$} \\
\hline 55 & [Yes] & [Yes] & {$[\mathrm{N}]$} \\
\hline 60 & {$[\mathrm{No}]$} & [Yes] & {$[\Xi]$} \\
\hline 61 & Yes & {$[\mathrm{No}]$} & {$[\mathrm{O}]$} \\
\hline 67 & Yes & No & $\Pi$ \\
\hline 72 & No & Yes & $\mathrm{P}$ \\
\hline 73 & [Yes] & {$[\mathrm{No}]$} & {$[\Sigma]$} \\
\hline 78 & No & Yes & $\mathrm{T}$ \\
\hline 79 & Yes & No & Y \\
\hline 84 & [Yes] & [Yes] & {$[\Phi]$} \\
\hline 90 & [Yes] & [Yes] & {$[\mathrm{X}]$} \\
\hline 96 & [Yes] & {$[\mathrm{No}]$} & {$[\Psi]$} \\
\hline 102 & [Yes] & [Yes] & {$[\omega]$} \\
\hline 107 & {$[\mathrm{No}]$} & [Yes] & {$[\overline{\mathrm{A}}]$} \\
\hline 108 & [Yes] & {$[\mathrm{No}]$} & {$[\overline{\mathrm{B}}]$} \\
\hline 114 & Yes & {$[\mathrm{No}]$} & $\bar{\Gamma}$ \\
\hline 119 & No & Yes & $\bar{\Delta}$ \\
\hline 120 & Yes & No & $\overline{\mathrm{E}}$ \\
\hline 125 & Yes & Yes & $\bar{Z}$ \\
\hline 131 & Yes & Yes & $\overline{\mathrm{H}}$ \\
\hline 137 & Yes & Yes & $\bar{\Theta}$ \\
\hline 143 & [Yes] & {$[\mathrm{No}]$} & {$[\overline{\mathrm{I}}]$} \\
\hline 149 & [Yes] & [Yes] & {$[\overline{\mathrm{K}}]$} \\
\hline 154 & {$[\mathrm{No}]$} & [Yes] & {$[\bar{\Lambda}]$} \\
\hline 155 & [Yes] & {$[\mathrm{No}]$} & {$[\overline{\mathrm{M}}]$} \\
\hline 161 & [Yes] & {$[\mathrm{No}]$} & {$[\overline{\mathrm{N}}]$} \\
\hline 166 & {$[\mathrm{No}]$} & [Yes] & {$[\bar{\Xi}]$} \\
\hline 167 & [Yes] & {$[\mathrm{No}]$} & {$[\overline{\mathrm{O}}]$} \\
\hline 172 & Yes & Yes & $\bar{\Pi}$ \\
\hline 178 & Yes & Yes & $\overline{\mathrm{P}}$ \\
\hline 184 & Yes & Yes & $\bar{\Sigma}$ \\
\hline 190 & Yes & No & $\overline{\mathrm{T}}$ \\
\hline
\end{tabular}


Table 5 (continued)

\begin{tabular}{llll}
\hline Cell & Lunar EP & Solar EP & Index \\
\hline 196 & {$[$ Yes $]$} & {$[$ Yes?] } & {$[\overline{\mathrm{Y}}]$} \\
201 & {$[$ No] } & {$[$ Yes $]$} & {$[\bar{\Phi}]$} \\
202 & {$[$ Yes $]$} & {$[$ No] } & {$[\bar{X}]$} \\
208 & {$[$ Yes $]$} & {$[$ No] } & {$[\bar{\Psi}]$} \\
213 & {$[$ Yes $]$} & {$[$ Yes $]$} & {$[\bar{\omega}]$} \\
219 & {$[$ Yes $]$} & {$[$ Yes $]$} & {$[\hat{\mathrm{A}}]$} \\
\hline
\end{tabular}

a solar EP but definitely not a lunar EP; and about cell 214, which may or may not have had a lunar EP but definitely not a solar EP.

We can now turn to the partition of the solar EPs into the groups described in the paragraphs of the BPI. For this purpose, Table 4 sorts the data of Table 2 (incorporating the additional deduced index letters from Table 3) in order of decreasing computed mean latitude. The same data are plotted in Fig. 9, with different markers to distinguish the EPs whose index letters are read in the paragraphs of the BPI.

Initially we use just the positions of the markers on the graph, and the problem we want to solve is where to place two horizontal lines representing limiting latitude values so that, combining the solar EPs represented by the markers between the lines with the almost completely known lunar EP pattern, we obtain a reconstruction of the whole set of EP cells and their index letters that matches not only the readings from the Saros Dial Scale but also the BPI. The top and bottom lines in the graph show a solution, with maximum $+1.45^{\circ}$ and minimum $-0.45^{\circ}$, though in both cases there is some tolerance. The upper limit must have been greater than $+1.4^{\circ}$ so that cell 13 can have a solar EP as attested on the Saros Dial Scale, whereas a value greater than about $+1.6^{\circ}$ would have resulted in a solar EP in the extant, vacant cell 189. The lower limit must have been below about $-0.4^{\circ}$, low enough to have a solar EP in cell 178. On the other hand, in order to have solar EPs with index letters $\bar{\omega}$ and $\hat{A}$ together in a single zone of latitude as recorded in BPI line 31, their cells have to have been 213 and 219, which implies that the lower limit was not much below $-0.5^{\circ}$ since there cannot have been a solar EP in cell 207 (otherwise the glyph indexed with $\bar{\omega}$ would have been the lunar glyph in cell 208). And it also follows that cell 2 did not have a solar EP since the latitude for such an EP would have been south of that for cell 207.

The notation $\hat{A}$ only makes sense as the first letter of a third alphabetic index letter sequence that, as it happens, did not go beyond one letter since cell 219 was the last one with EPs in the Saros. We thus conclude that the previously undetermined lunar EP was in cell 213, not 214, and that there were just 49 glyphs in total, so that by a happy chance, practically all uncertainties about how the lunar and solar EPs were distributed and lettered along the Saros Dial Scale now vanish (Table 5). The only remaining uncertainty is whether cell 196 (indexed $\bar{Y}$ ) had a solar EP as well as its lunar EP; this seems likely, however, since the associated latitude is just north of that of the northernmost certain solar EP in cell 13. 
The full sequence of index letters for the solar EPs, in descending order of our recomputed mean latitudes, is as follows:

\section{(4) $\overline{\mathrm{Y}} \Gamma \overline{\mathrm{K}} \Xi \underline{\omega}|\underline{\overline{\mathrm{A}} \mathrm{N} \bar{\Lambda} \mathrm{B} \bar{\Phi}}| \underline{\bar{\Sigma} Z \bar{\Theta} \mathrm{PX} \bar{\Delta}} \Lambda \bar{\Xi}|\underline{\hat{\mathrm{A}} \bar{\omega} \bar{\Pi} \mathrm{Z} \overline{\mathrm{Z}} \Phi}| \underline{\mathrm{T} \overline{\mathrm{H}} \Theta \overline{\mathrm{P}}}$}

Underlined index letters are legible with sufficient security in the BPI. Vertical strokes indicate known locations of the divisions between BPI paragraphs. A simple symmetrical scheme that fits the divisions is:

$$
\begin{aligned}
& \text { BPI4: }+1.45^{\circ}>\beta>+1.15^{\circ}\left(0.3^{\circ}\right) \\
& \text { BPI9: }+1.15^{\circ}>\beta>+0.75^{\circ}\left(0.4^{\circ}\right) \\
& \text { BPI18: }+0.75^{\circ}>\beta>+0.25^{\circ}\left(0.5^{\circ}\right) \\
& \text { BPI29: }+0.25^{\circ}>\beta>-0.15^{\circ}\left(0.4^{\circ}\right) \\
& \text { BPI36: }-0.15^{\circ}>\beta>-0.45^{\circ}\left(0.3^{\circ}\right)
\end{aligned}
$$

There are only two discrepancies between the reconstructed scheme and the BPI readings, both involving order of index letters within the single rows. In BPI19, we have $\bar{\Sigma}$ following $Z \bar{\Theta}$; this discrepancy was previously noted and is probably explicable as an engraver's delayed correction of an accidentally skipped letter. ${ }^{43}$ In BPI31, we have $\bar{\omega}$ before $\hat{A}$, which could be another engraver's error, but as we shall see presently, is more likely to be the result of slightly different calculations of the latitudes.

Did the paragraph ending with BPI19 apply to all eight solar EPs that should have come between those of BPI10 and BPI31? We think it surely did, with the row continued on a second line 20 of which at best we have only faint traces of the first letter as a result of the severe surface damage along the right side of this part of the Back Plate in Fragment A. Freeth's alternative proposal of a paragraph belonging between that of BPI19 and that of BPI31, but inscribed along the lost left side of the Back Plate, is less credible now that BPI5 has been confirmed as the index letter line of the first paragraph of solar EPs. Hence, we conclude that there were five zones of solar EPs, with the central one bisected by the line of symmetry of the whole scheme at $\beta=+0.5^{\circ}$.

\subsection{Further consideration of the Mechanism's eclipse prediction function}

Making allowance for the crudeness of a solar eclipse theory in which the effect of parallax is treated in such a highly reductive manner, a northward shift by $+0.5^{\circ}$ of the latitudinal belt within which solar eclipses are considered possible (i.e., an

43 Freeth (2014, 7); Anastasiou et al. (2016, 198). 
assumption that the Moon's apparent latitude is shifted southward by parallax by this amount) is a reasonable parameter. It might have been obtained through a schematic calculation on the assumption that the conjunction occurs at a point on the observer's meridian and that the entire parallax can be equated with its latitudinal component. Using this simplification and also assuming a mid-Mediterranean latitude of $36^{\circ}$ (the conventional "parallel through Rhodes" of ancient geography), we have

$$
D_{\text {Moon }} \approx \sin \left(36^{\circ}\right) / \sin \left(0.5^{\circ}\right) \approx 67 \text { earth radii }
$$

which is of the right order of magnitude for the Moon's distance from the Earth and in fact is very close to one of Hipparchus's values (67 1/3 earth radii) though this is not a compelling reason to connect the model with Hipparchus's work, given the number of assumptions involved in our calculation.

We noted above that one of the two discrepancies between the ordering of index letters generated by the latitude model (Table 4; Fig. 9) and the BPI is that in line $31 \bar{\omega}$ precedes $\hat{A}$ instead of following it. Since the EPs in question are in cells 213 and 219, at the very end of the Saros, one might suspect that the discrepancy is not the result of an error but arises from a difference between the way that we calculated the mean lunar latitudes and the ancient derivation of the Mechanism's eclipse data. In formula (2), the choice of $\beta_{\max }$ and the particular trigonometrical relation are not relevant to the present question, since even an approximate relation that makes latitude strictly dependent on elongation from the node (e.g., making it proportional to the sine of the elongation) will result in the same ranking of EPs in order of decreasing latitude.

The choice of period relation, however, as defined by $S$ and $D$, is relevant. The length of the mean dracontic month in mean synodic months (i.e., $S / D$ ) according to the Saros period relation is approximately 0.9214876 , slightly less than the true value (approximately 0.9214926). Though the error is small, it is enough so that by the end of a Saros it could potentially affect which of two almost equal mean latitudes of EPs is the greater. We know from Ptolemy, Almagest 4.2 that Hipparchus knew the more accurate period relation of the Babylonian System B lunar theory:

5458 synodic months $=5923$ dracontic months

from which $S / D$ is approximately 0.9214925 . Now if we recalculate the mean latitudes using

$$
\sin (\beta)=\sin \left(5^{\circ}\right) \sin \left(360^{\circ} \times((5923-5458) / 5458) \times i+125.0^{\circ}\right)
$$

and sort the solar EPs in order of decreasing latitude as before, we now obtain this sequence:

\section{$\overline{\mathrm{Y}} \Gamma \overline{\mathrm{K}} \Xi \underline{\omega}|\underline{\overline{\mathrm{A}} \mathrm{N} \bar{\Lambda} \mathrm{B} \bar{\Phi}}| \underline{\bar{\Sigma} Z \bar{\Theta} \mathrm{PX} \bar{\Delta} \Lambda \bar{\Xi}|\underline{\underline{\omega} \hat{A} \bar{\Pi} K \bar{Z} \Phi}| \underline{\mathrm{T}} \Theta \overline{\mathrm{P}}}$}


which differs from (4) only in placing $\bar{\omega}$ and $\hat{A}$ in the order they appear in BPI31. It thus appears that the solar eclipse theory underlying the Mechanism's solar EP distribution and the ordering and grouping of EPs according to latitude assumed a more accurate latitudinal period relation than the Saros.

The constant $125.0^{\circ}$ in (7), which represents the assumed mean elongation of the Moon from the ascending node at the mean conjunction preceding that of cell 1 , is tightly constrained. Using $124.9^{\circ}$ generates an index letter sequence in which there are many reversals of adjacent pairs of index letters compared with (8), while using $125.2^{\circ}$ generates the sequence of (4). On the other hand, the pattern of cells with lunar EPs implies an elongation for the conjunction preceding that of cell 1 between $127.1^{\circ}$ and $127.7^{\circ} .^{44}$ It would appear, then, that the Mechanism's lunar EPs were obtained by a theory differing from that used for the solar EPs. It deserves noting that, according to the dating of the Saros Dial's eclipse predictions deduced by Carman and Evans (2014) and by Freeth (2014), the "cell 0" mean conjunction was that of April 27, 205 BC, and according to Ptolemy's lunisolar theory, the elongation of the mean Moon from the ascending node at the mean conjunction on that date was $124.6^{\circ}$, in close agreement with the theory underlying the solar EPs.

\section{Data access}

CT data for Fragment A may be accessed at https://doi.org/10.7910/DVN/ UCXZWU and partial data for Fragment F (specifically for the BPI) at https://doi. org/10.7910/DVN/GKYKOV, cited above as Freeth 2018. For information regarding CT data for the other fragments, see http://www.antikythera-mechanism.gr/data. All the PTM files of the Antikythera Mechanism may be accessed at http://www.antik ythera-mechanism.auth.gr/PTM and at https://archive.nyu.edu/handle/2451/44192.

Acknowledgements This article is partly based on CT data (courtesy X-Tek Systems, now owned by Nikon Metrology, 2005) processed, with permission, from the archive of experimental investigations by the Antikythera Mechanism Research Project in collaboration with the National Archaeological Museum of Athens. Equipment loaned by X-Tek Systems Ltd (now owned by Nikon Metrology) was used to collect the data. In particular, we want to thank John Seiradakis, Mike Edmunds and Xenophon Moussas for releasing these data, which have been reconstructed and analyzed using Volume Graphics StudioMax 3.2 software. Thanks are also owed to Cyrus Taylor, former Dean of the College of Arts and Sciences of Case Western Reserve University, for his generous support in purchasing the software used for viewing CT data, Mark Griswold, Director of the Interactive Commons of CWRU, for providing access to a highpowered computer to use it, Kamil Szepanski of Volume Graphics for assistance with CT volume reconstruction, and Jared Bendis in the Freedman Center of Case Western for helping with technical aspects of Adobe Illustrator. We have also made use of PTM data (courtesy Hewlett-Packard 2005) obtained through the same collaboration between the National Archaeological Museum and the Antikythera Mechanism Research Project. We also wish to thank Niels Bos for several excellent photographs of the inscriptions on Fragment A (cited in the apparatus).

\footnotetext{
${ }^{44}$ Using $125.0^{\circ}$, we would have lunar EPs in cell 38 instead of 37, in cell 126 instead of 125 (which is a surviving lunar glyph), and in cell 214 instead of 213.
} 


\section{Compliance with ethical standards}

Conflict of interest On behalf of all authors, the corresponding author states that there is no conflict of interest.

Open Access This article is distributed under the terms of the Creative Commons Attribution 4.0 International License (http://creativecommons.org/licenses/by/4.0/), which permits unrestricted use, distribution, and reproduction in any medium, provided you give appropriate credit to the original author(s) and the source, provide a link to the Creative Commons license, and indicate if changes were made.

\section{References}

Anastasiou, M., Y. Bitsakis, A. Jones, J.M. Steele, and M. Zafeiropoulou. 2016. Inscriptions of the Antikythera Mechanism. 4. The Back Dial and Back Plate Inscriptions. Almagest 7 (1): 138-215.

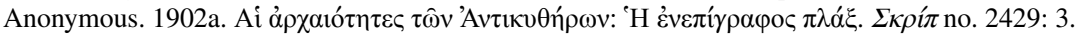

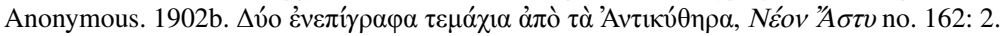

Bevan, G., A. Jones, and D. Lehoux. forthcoming. The Miletus Parapegma and the Keskintos Astronomical Inscription: New Evidence from Reflectance Transformation Imaging. Zeitschrift für Papyrologie und Epigraphik.

British Museum. 1893. Greek Papyri in the British Museum. London: Facsimiles.

Carman, C.C., and J. Evans. 2014. On the Epoch of the Antikythera Mechanism and Its Eclipse Predictor. Archive for History of Exact Sciences 68: 693-774.

Freeth, T. 2014. Eclipse Prediction on the Ancient Greek Astronomical Calculating Machine Known as the Antikythera Mechanism. PLoS ONE 9 (7): e103275.

Freeth, T. 2018. Data for Freeth, T., Revising the Eclipse Prediction Scheme in the Antikythera Mechanism, https://doi.org/10.7910/DVN/GKYKOV, Harvard Dataverse, V1.

Freeth, T. 2019. Revising the Eclipse Prediction Scheme in the Anitkythera Mechanism. Palgrave Communications 5, article no. 7: https://www.nature.com/articles/s41599-018-0210-9.

Freeth, T., Y. Bitsakis, X. Moussas, J.H. Seiradakis, A. Tselikas, H. Mangou, M. Zafeiropoulou, R. Hadland, D. Bate, A. Ramsey, M. Allen, A. Crawley, P. Hockley, T. Malzbender, D. Gelb, W. Ambrisco, and M.G. Edmunds. 2006. Decoding the Ancient Greek Astronomical Calculator Known as the Antikythera Mechanism. Nature 444: 587-591. Supplementary information, http://www.natur e.com/nature/journal/v444/n7119/suppinfo/nature05357.html.

Freeth, T., A. Jones, J.M. Steele, and Y. Bitsakis. 2008. Calendars with Olympiad Display and Eclipse Prediction on the Antikythera Mechanism. Nature 454: 614-617. Supplementary Notes (amended June 2, 2011), http://www.nature.com/nature/journal/v454/n7204/extref/nature07130-s1.pdf.

Gibson, A. 2018. Antikythera Fragment A Scan A6. Harvard Dataverse, V1. https://doi.org/10.7910/ DVN/UCXZWU.

Iversen, P. 2017. The Calendar on the Antikythera Mechanism and the Corinthian Family of Calendars. Hesperia 86: 129-203.

Jones, A. 1999. Astronomical Papyri from Oxyrhynchus. 2 vols. in 1. Philadelphia: Memoirs of the American Philosophical Society 233.

Jones, A. 2006a. IG XII,1 913: An Astronomical Inscription from Hellenistic Rhodes. ZPE 158: 104-110.

Jones, A. 2006b. The Keskintos Astronomical Inscription Text and Interpretations. SCIAMVS 7: 3-41.

Jones, A. 2017. A Portable Cosmos: Revealing the Antikythera Mechanism, Scientific Wonder of the Ancient World. New York: Oxford University Press.

Lougovaya, J. 2015. Greek Insccriptions in Ptolemaic Narmouthis. In Von der Pharaonenzeit bis zur Spätantike: kulturelle Vielfalt im Fayum. Akten der 5. Internationalen Fayum-Konferenz, 29. Mai bis 1. Juni 2013, Leipzig, N. Quenouille, ed. Wiesbaden.

Pakzad, A., F. Iacoviello, A. Ramsey, R. Speller, J. Griffiths, T. Freeth, and A. Gibson. 2018. Improved X-ray Computed Tomography Reconstruction of the Largest Fragment of the Antikythera Mechanism, an Ancient Greek Astronomical Calculator. PLOS ONE 13 (11): e0207430. https://doi. org/10.1371/journal.pone.0207430.

Price, D. 1974. Gears from the Greeks. Transactions of the American Philosophical Society N.S. 64 (7): 1-70. 


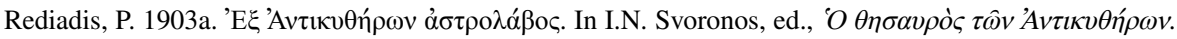
Athens. 43-51.

Rediadis, P. 1903b. Der Astrolabos von Antikythera. In I.N. Svoronos, ed., Die Funde von Antikythera. Athens. 43-51.

Steele, J.M. 2011. Visual Aspects of the Transmission of Babylonian Astronomy and Its Reception into Greek Astronomy. Annals of Science 68 (4): 453-465.

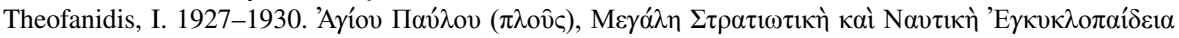
1:83-96 [pp. 89-96 are erroneously numbered 97-104].

Publisher's Note Springer Nature remains neutral with regard to jurisdictional claims in published maps and institutional affiliations. 